\title{
ESTADO DE DERECHO Y PLURALISMO RELIGIOSO ${ }^{1}$
}

\author{
Arturo Calvo Espiga \\ Abogado del Tribunal de la Rota de Roma \\ Catedrático de Derecho Eclesiástico \\ Universidad de Málaga
}

«El hombre podrá prescindir de una fe sólo cuando haya evolucionado hasta situarse más allá de la experiencia de la incertidumbre»( M. Greeley)

\begin{abstract}
Sumario. 1. Delimitación del entorno hermenéutico. 1.1. Los derechos humanos como horizonte jurídico del Estado. 1.2. Razón y razonabilidad como lugares hermenéuticos. 2. Acercamiento al entorno histórico-jurídico. 3. El Estado de Derecho como lugar jurídico. 3.1. El Estado, concepto jurídico-político y realidad social. 3.2. El Estado de Derecho, legitimación jurídica de la estructura estatal. 3.3. El Estado social. 4. El pluralismo religioso como identidad democrática del Estado. 4.1. Sentido del término pluralismo. 4.2. El pluralismo político, principio y valor del ordenamiento. 4.3. Pluralismo y ejercicio de las creencias religiosas: paradoja y compromiso. 5. A modo de colofón conclusivo.
\end{abstract}

En consonancia con el título que encabeza esta reflexión me ha parecido conveniente ofrecer determinadas concreciones y matizaciones conceptuales o terminológicas, en orden a precisar el contenido o significado de las categorías sobre las que articularé estas páginas. Por otra parte, el hecho de relacionar Estado y Religión, bien que desde la perspectiva socio-jurídica que exigen tanto la actual conformación de los Estados democráticos como la comprensión y sentido del papel y función de la Religión en la sociedad contemporánea, no es novedoso ni para el jurista, ni para el sociólogo, ni mucho menos para el historiador, sobre todo si contemplamos los últimos dos milenios de la historia de Occidente.

Aun cuando los límites de este género académico configuren de forma estricta el contenido y extensión de los asuntos a tratar, sobre todo desde la perspectiva de la configuración interna de sus estructuras o desde los fundamentos teológicos de las Confesiones religiosas, el marco o telón de fondo de esta exposición ha de ser la significativa presencia, a pesar de las fuertes corrientes secularizadoras, que las cuestiones relacionadas con lo sagrado mantienen en nuestras sociedades. La disminución en la práctica cultual de

${ }^{1}$ El presente estudio se ha realizado dentro del marco de las actividades del Grupo de Investigación, Implicaciones jurídicas de la interculturalidad social y religiosa, SEJ 344 de la Junta de Andalucía y ha contado con la ayuda del Centro de Estudios anejo a la Iglesia Nacional Española en Roma. 
las religiones tradicionales y mayoritarias en nuestro entorno europeo contrasta, sin embargo, con el crecimiento y extensión de nuevas formas de presencia, identidad y testimonio militante de lo sagrado ${ }^{2}$.

Así pues, en un mundo, al menos aparentemente, secularizado, por parte de las Confesiones religiosas y de la propia sociedad se reclama a la civitas, cada vez con mayor urgencia, no sólo garantías para su propio desarrollo y el de su actividad proselitista, sino el reconocimiento de su papel y misión en el espacio público ${ }^{3}$. Presencia en el espacio público que debe ser garantizada y protegida por un Estado exquisitamente neutro e independiente por lo que se refiere a la estructura y funcionamiento interno de las propias Confesiones, así como respecto a los posibles conflictos que puedan surgir en el seno de las referidas Confesiones.

No se debe perder de vista, además, que la problemática que analizamos en esta sede está firmemente enraizada en lo más íntimo del ser personal,

${ }^{2}$ En plena efervescencia secularizadora y cuando la teología de la muerte de Dios era referencia obligada para teólogos, sociólogos, filósofos y eclesiásticos europeos y americanos, Greeley, eminente sociólogo y escritor norteamericano, finalizaba un precioso libro sobre el anhelo y búsqueda de lo religioso en la ciudad secular con estas palabras: «Y, por si faltaba algo, el profesor Harvey Cox ya ha emprendido su peregrinación desde la ciudad secular hasta la ciudad festiva, situada en lo alto de una montaña cuyo nombre suena de manera muy parecida a Camelot, que, nótese bien, era un lugar mitológico en tiempos del Rey Arturo y lo era todavía en los años sesenta del siglo XX» (GreELEY, A. M., Un secular man. The persistence of religion, Schocken Books Nueva York, 1972, p. 278). No en vano la secularización no va más allá de ser, tal como se ha presentado hasta el momento, una quimera mítica disfrazada de racionalismo.

3 «Convinzione comune ai diversi autori e alle diverse prospettive di ricerca sembra essere che le questioni relative alla 'religione' sono strettamente congiunte alle trasformazioni subite dall'uomo nell'epoca moderna e contemporanea, che vede il passaggio dall'epoca della secolarizzazione all'epoca del postsecolarismo. Fino agli anni Settanta costituiva punto di riferimento la tesi di Harvey Cox, il quale ne La città secolare scriveva: «Il mondo sta diventando sempre più soltanto mondo»... Ma già dalla metà degli anni Settanta il processo di secolarizzazione subisce un mutamento: «Prende forma un nuovo discorso religioso non più per cercare un adeguamento ai valori secolari, ma per ridare un fondamento sacro all'organizzazione della società, modificandola se necessario. Attraverso le sue molteplici espressioni questo discorso esalta il superamento di una modernità fallita, attribuendo insuccessi e disorientamenti all'allontanamento da Dio» ${ }^{(*)}$. La filosofia politica e sociale, quale emerge in un'epoca culturalmente qualificata come 'postmoderna', sembra attribuire un grande significato al 'postsecolarismo', inteso come la nuova comprensione del significato e del valore della religione dopo la secolarizzazione» (Possenti, V., «Editoriale», en IdEm (ed.), Ritorno della religione? Tra ragione, fede e società, Guerini Studio, Milán, 2009, p. 9). En parecida línea y dentro del mismo volumen que corresponde al Annuario di Filosofia del año 2009, puede verse también: GABELLIERI, E., «Ethique et «vie publique», comme médiations entre religion et politique», pp. 119-138 y GATTI, R., «Il problema teologico-politico e il retorno della Religione nella sfera pubblica», pp. 139-164. 
así como en el ejercicio de los derechos básicos y fundamentales de los que es titular. Desde esta perspectiva personal/personalista abordaremos el papel del Estado y toda su estructura en el reconocimiento y garantía de la autonomía de la sociedad civil y de las personas que son antes miembros de la sociedad que ciudadanos del Estado que, en cuanto auténticamente democrático, la ordena y sirve como instrumento para que aquella y los ciudadanos que la conforman alcancen sus fines.

La relación del Estado con las Confesiones religiosas y las consecuencias jurídicas que de aquella derivan tienen una larga biografía, aunque en esta exposición nos ceñiremos, con la brevedad, que requiere el caso a la experiencia que ofrece la historia del Cristianismo desde su aparición en pleno florecimiento del Imperio romano. El estudio de la exigencia que la práctica religiosa plantea al Estado de derecho lo abordamos desde una doble perspectiva hermenéutica: la propia que exige la opción por los derechos humanos de los sistemas democráticos contemporáneos y la que se deriva del lugar preeminente que ha de ocupar la racionalidad en todo análisis que afecte a la persona y a su protagonismo en la sociedad. Desde esta opción metodológica nos preguntaremos por los elementos fundamentales que definen el Estado de derecho así como por sus exigencias jurídicas y políticas y por cómo se han de proyectar en su relación con las Confesiones religiosas, buscando, sobre todo, si la actitud de positiva colaboración que el Estado está llamado a mantener con las Confesiones religiosas en cuanto cauce de expresión de uno de los más íntimos derechos fundamentales de sus ciudadanos es exigencia de la misma naturaleza jurídica del Estado de derecho.

\section{DELIMITACIÓN DEL ENTORNO HERMENÉUTICO.}

Antes de abordar la problemática a que se refiere el título que encabeza este estudio, interesa poner de manifiesto el entorno metodológico y, en cierto modo, de contenido desde el que abordaré el asunto sobre el que versa esta exposición, puesto que difícilmente en cuestiones jurídicas fundamentales, como considero la que aquí abordaremos, los contenidos pueden permanecer inmunes a la influencia de la metodología utilizada en su tratamiento. Me refiero al papel fundamental que la observancia, respeto y práctica de los derechos humanos desempeñan en la articulación del Estado de derecho.

\subsection{Los derechos humanos como horizonte jurídico del Estado.}

Al referirnos a los derechos humanos, no podemos dejar de lado la radical polisemia, equivocidad, en tantos casos, del topos derechos humanos ${ }^{4}$.

${ }^{4}$ Cf. Brow, S. M., «Inalienable Right», Philosophical Review 64, 1955, pp. $192-$ 211; CAlvo Espiga, A., «Pautas para el análisis de un anacronismo jurídico: ¿'Derechos humanos' en la Iglesia?», en Pluralismo socio-cultural y fe cristiana, Mensajero, ESET y Universidad de Deusto, Bilbao-Vitoria, 1990, pp. 366-370; EllacuríA, I., «Historización de los derechos humanos desde los pueblos oprimidos y las mayorías populares», 
Por ello, de ninguna manera se ha de dar por supuesta la significación de esta locución. Sin entrar en el detalle de esta problemática, sí que conviene apuntar, a modo de criterio orientativo, el hecho de que en amplios sectores de la doctrina constitucionalista se está imponiendo progresivamente la tendencia a sustituir la conceptualización derechos humanos por la de derechos fundamentales. Así pues, desde la perspectiva de los ordenamientos jurídicos contemporáneos los derechos humanos sólo se asumen en cuanto derechos fundamentales, es decir, en la medida en que hayan sido formalmente constitucionalizados: de este modo, a los derechos humanos sólo les dota de efectividad jurídica el hecho de su inserción positiva en los textos normativoconstitucionales 5 . Como consecuencia de este principio, no es de extrañar que cada vez adquieran más fuerza aquellas líneas doctrinales que defienden el sinsentido que supone, a partir de los ordenamientos constitucionales actualmente vigentes, hablar hoy de unos derechos humanos inherentes a la persona y previos a los ordenamientos constitucionales de carácter democrático $^{6}$.

No faltan, sin embargo, voces que, a diferencia de los anteriores, estiman que el propio término derecho fundamental admite, al menos, una duplicidad de significado. Por una parte, hablar de derechos fundamentales sería equivalente a reconocer la preexistencia, respecto al Estado, de la persona humana en cuanto sujeto jurídico; y, por otra, equivaldría a garantizar un espacio propio de autonomía para el individuo, independientemente del Estado. En este sentido ha podido afirmarse que «los derechos del hombre constituye una de las más grandes invenciones de nuestra civilización» ${ }^{7}$. Y ello porque el potencial socio-jurídico de los propios derechos humanos ha permeabilizado de tal modo la conformación constitucional de los Estados que incluso ha llegado a transformar la misma noción originaria de Estado de derecho que, de medio garantizador de la aplicación del derecho, se ha convertido en promotor de la realización de los derechos del hombre no sólo

Lumen 39, 1990, pp. 9-19; GARcía BARBEREnA, T., «Adulterio casto», Revista Española de Derecho Canónico 17, 1962, pp. 24-261; PuY MuÑoz, F., Tópica jurídica, Imprenta Paredes, Santiago de Compostela, 1984, pp. 372-483; IDEM, «Algunos tópicos actuales sobre derechos humanos», Estudios de filosofía del derecho y ciencia jurídica, t. 2, Madrid 1985, pp. 275-280; IDEM, «El tópico «derechos humanos»», Revista General de Legislación y Jurisprudencia 95, 1987, pp. 200-202.

${ }^{5}$ Así, por ejemplo, se expresa la Constitución Española: «Las normas relativas a los derechos fundamentales y a las libertades que la Constitución reconoce, se interpretarán de conformidad con la Declaración Universal de Derechos Humanos y los tratados y acuerdos internacionales sobre las mismas materias ratificados por España» (CE, art. 10. 2).

${ }^{6}$ Cf. Soriano, R., «¿Es iusnaturalista la Constitución Española de 1978?», Revista de las Cortes Generales, n. 12, 1987, pp. 109-159.

7 Nino, C. S., Ética y Derechos humanos, Paidos Studio, Buenos Aires, 1984, p. 13. 
formal sino también materialmente, como queda por ejemplo imperado en el artículo 9, 2 de la Constitución Española ${ }^{8}$, pasando a ser determinado o calificado el Estado de derecho como social y democrático ${ }^{9}$.

El principio de que las leyes encuentran siempre un límite en derechos preexistentes del individuo que las mismas leyes no pueden sobrepasar constituye uno de los fundamentos del Estado democrático, en la medida en que supone una auténtica revolución en la forma de entender las relaciones políticas al contraponer al hombre considerado como individuo singular a la sociedad y, en última instancia, al Estado; y al considerar el derecho como antecedente o previo al deber, en contra de lo que había sido común en una larga tradición jurídica que se extiende desde Cicerón hasta Pufendorf.

${ }^{8}$ «Corresponde a los poderes públicos promover las condiciones para que la libertad y la igualdad del individuo y de los grupos en que se integran sean reales y efectivas; remover los obstáculos que impidan o dificulten su plenitud y facilitar la participación de todos los ciudadanos en la vida política, económica, cultural y social». Resulta paradójico que el único desarrollo normativo que haya tenido este párrafo, así como el propio artículo $10 \mathrm{CE}$, se haya realizado, hasta el momento, por el escueto artículo 1 de la Ley 51/2003, de 2 de diciembre, de Igualdad de oportunidades, no discriminación y accesibilidad universal de las personas con discapacidad: «1. Esta Ley tiene por objeto establecer medidas para garantizar y hacer efectivo el derecho a la igualdad de oportunidades de las personas con discapacidad, conforme a los artículos 9.2, 10, 14 y 49 de la Constitución.

A estos efectos, se entiende por igualdad de oportunidades la ausencia de discriminación, directa o indirecta, que tenga su causa en una discapacidad, así como la adopción de medidas de acción positiva orientadas a evitar o compensar las desventajas de una persona con discapacidad para participar plenamente en la vida política, económica, cultural y social.

«2. A los efectos de esta Ley, tendrán la consideración de personas con discapacidad aquellas a quienes se les haya reconocido un grado de minusvalía igual o superior al 33 $\%$. En todo caso, se considerarán afectados por una minusvalía en grado igual o superior al $33 \%$ los pensionistas de la Seguridad Social que tengan reconocida una pensión de incapacidad permanente en el grado de total, absoluta o gran invalidez, y a los pensionistas de clases pasivas que tengan reconocida una pensión de jubilación o de retiro por incapacidad permanente para el servicio o inutilidad.

«La acreditación del grado de minusvalía se realizará en los términos establecidos reglamentariamente y tendrá validez en todo el territorio nacional».

9 Cf. Hollerbach, A., "Grundwerte und Grundrechte in der Gesellschaft und im Staat», en Corecco, E., Herzog, H. y Scola, A. (eds.), Die Grundrechte des Christen in Kirche und Gessellschaft, Herder Verlag, Friburgo-Suiza, Friburgo de Brisgovia y Milán, 1981, pp. 811-833. Para una descripción más detallada de las distintas comprensiones de los derechos humanos operantes en la dogmática jurídica contemporánea, puede verse Calvo Espiga, A., «Pautas para el análisis de un anacronismo jurídico...», cit., pp. 367369. 
Como colofón de esta polisemia o quizás de esta equívoca complejidad significativa del término derechos humanos cabe una breve referencia al contenido y consecuencias del párrafo 2 del artículo 29 de la Declaración Universal de Derechos del Hombre, de 10 de diciembre de $1948^{10}$. Cláusula que, al determinar la entidad y cualidad de las limitaciones admisibles en el ejercicio de los derechos humanos, configura de hecho un modo concreto y preciso de entender los derechos humanos, constituyendo, aunque de forma indirecta, una nueva conceptualización de los mismos. Se establece en la norma de referencia que las limitaciones en el ejercicio de los derechos humanos contemplados en la Declaración deben ser «determinadas por la ley» $\mathrm{y}$, en concreto, establece como tales limitaciones la moral, el orden público y el bienestar general en una sociedad democrática. Nos hallamos, pues, ante unos conceptos jurídicamente tan vagos e imprecisos, por su generalización, que de nuevo, para su concreción, se hace necesario recurrir, según previsión del propio texto de la Declaración, a los ordenamientos propios de cada Estado. En definitiva, resulta que las elecciones definitivas en todo lo referido con el ejercicio y respeto de los derechos humanos son confiadas al ordenamiento interno de cada Estado.

Queda, pues, patente como en la formulación de este artículo 29 adquiere inusitada vigencia el que se ha denominado mito de la ley, tan presente en las grandes declaraciones politicas del siglo XVIII y de forma especial en la francesa inspirada directamente, por lo que se refiere a esta cuestión, en el pensamiento de Rousseau ${ }^{11}$. De la discusión que precedió durante los años 1946 a 1948 a la Declaración de la ONU se concluye idéntica impresión, al asumir como principio la presunción de ecuanimidad, justicia, control y no arbitrariedad de la ley dado su carácter general (erga omnes) y el hecho de que normalmente sea elaborada por órganos democráticos. Sin embargo,

${ }_{10}$ «En el ejercicio de sus derechos y en el disfrute de sus libertades, toda persona estará solamente sujeta a las limitaciones establecidas por la ley con el único fin de asegurar el reconocimiento y el respeto de los derechos y libertades de los demás, y de satisfacer las justas exigencias de la moral, del orden público y del bienestar general en una sociedad democrática».

${ }^{11}$ En sentido distinto la que, con toda probabilidad, puede considerarse como la primera formulación jurídica y orgánicamente estructurada de derechos humanos es la declaración realizada por el Concilio Provincial de Charcas, actual Sucre, el año 1774: «La déclaration du concile de Charcas, approuvée d'abord par le concile lui-même et renforcée dans la suite par le «Real acuerdo» de la «Audiencia»; replacée dans l'histoire, c'est à dire, dans cette longue gestation et ce lent cheminement des idées; considérée en fonction de la formulation toujours plus précise des théories en fonction des réalités les plus diverses et des institutions, constitue, semble-t-il, dans l'ordre chronologique, un des premiers maillons de la grande chaîne des déclarations des droits de l'homme. Elle est antérieure, en tout cas, à celle des Etats-Unis de l'Amérique du Nord (1778) et à celle de la France (1789)» (SoRIA-VASCO, J.-A., «Le Concile provincial de Charcas de 1774 et les déclarations des Droits de l'homme», L'Année Canonique 15, 1971, p. 514). 
con demasiada frecuencia, la experiencia demuestra que, incluso en el caso de sistemas tenidos por democráticos, la ley puede ser elaborada, manipulada o tergiversada a gusto y conveniencia del poder ejecutivo, bien cuando acontece una situación de identidad-continuidad entre el Gobierno y la mayoría parlamentaria de la que procede, o cuando la institución parlamentaria no es otra cosa que una formalidad cara a la galería que, por distintas circunstancias, no es capaz de expresar exigencias o pareceres distintos o contrapuestos a los del ejecutivo.

La raíz y el lazo común de los derechos humanos es, como se expresa en el artículo 1 de la Declaración de la ONU, la dignidad humana ${ }^{12}$. Aunque los derechos humanos son plurales y susceptibles de aumento o progreso cuantitativo, para la dignidad humana sólo existe el singular. La dignidad humana es una, única e indivisible, idéntica para y en cualquier ser humano; y constituye el nervio y corazón de la doctrina de los derechos humanos. La dignidad humana no es graduable, o se da plenamente o no se da en absoluto. La dignidad designa una propiedad esencial e inescindible del ser humano, al margen y más allá de cómo filosofías e ideologías conciban su contenido. La dignidad humana, pues, equivale al valor inapreciable del ser humano puesto que el hombre es un fin en si mismo y no puede ser reducido a objeto de nada ni de nadie, ni, en consecuencia, le puede ser asignado precio que posibilite su permuta ${ }^{13}$. Si bien como ya pusiera de relieve Berlin y más recientemente Francesca De Vecchi, sólo podrá hablarse de dignidad de la persona, en un sentido pleno y jurídica y éticamente relevante, cuando el valor en sí de la dignidad sea aceptado por el otro ${ }^{14}$. O, dicho de otro modo, la dignidad se plenifica, en cuanto valor, por la aceptada relación hacia el otro,

12 «Todos los seres humanos nacen libres e iguales en dignidad y derechos y, dotados como están de razón y conciencia, deben comportarse fraternalmente los unos con los otros». En la misma línea se manifiesta la Constitución Española en el párrafo 1 de su artículo 10: «La dignidad de la persona, los derechos inviolables que le son inherentes, el libre desarrollo de la personalidad, el respeto a la ley y a los derechos de los demás son fundamento del orden político y de la paz social».

${ }^{13}$ Cf. Kant, I., Fundamentación de la metafísica de las costumbres, tr. M. García Morente, Espasa Calpe, S. A., Madrid, 19817 , pp. 90-93.

${ }^{14}$ Según Berlin, el hombre libre de Kant no necesita reconocimiento público alguno para ser interiormente libre. Aunque sea tratado como un medio en orden a conseguir un fin totalmente extraño a su ser hombre, nos hallaremos ante una injusticia de quien lo explota, pero su estatuto «nouménico» permanece intacto y siempre será perfectamente libre y plenamente humano cualquiera sea el modo en que haya sido tratado. Pero, para Berlin, la relación a y con los otros se convierte en elemento fundamental de la propia persona, puesto que, según él «yo no soy nada si no soy reconocido». Cf. BerLin, I., Two Concepts of Liberty, Oxford University Press, Oxford, 1958, p. 41; De VECCHI, F., «Introduzione. Il fondamento assoluto e plurale dei diritti umani», en Hersch, J., I diritti umani da un punto di vista filosofico, Bruno Mondadori, Milán, 2008, p. 33: la edición italiana de esta obra de Hersch ha sido realizada por F. De Vecchi. 
aun cuando la consecuencia de la reciprocidad pueda llegar, en el peor de los casos, a concretarse en la violación - negación de la propia dignidad. De este modo, quien utiliza a otro ser humano, aunque en el fondo no cercenara su íntima dignidad (Kant), provoca la violación o quiebra de su propia dignidad en la medida en que ha procurado la anulación de la ajena. En razón, pues, de que la dignidad del hombre es una, indivisible y no graduable, no cabe sino aceptar que los derechos del hombre son una totalidad, una realidad o unidad en si mismos y que, por tanto, no pueden ser añadidos o sustraídos según coyunturas o conveniencias ${ }^{15}$.

La división o especificidad de los derechos humanos tal como actualmente se ordenan o sistematizan por parte de la dogmática jurídica es, probablemente, deudora de su propia historia. Tras la experiencia de la segunda guerra mundial era lógico que en la articulación de los derechos humanos primasen dos líneas fundamentales: la que determina los conocidos como derechos humanos individuales, protectores del individuo frente al Estado y a los poderes fácticos sociales; y la que sustenta los denominados derechos humanos sociales y, los con ellos necesariamente relacionados, económicos. La pobreza, miseria en tantos casos, del mal denominado Tercer Mundo y su expansión tanto cuantitativa como cualitativa han conformado una nueva categoría, la del derecho a la existencia. Por otra parte, la progresiva complejidad de las relaciones políticas y sociales en un mundo que ha aproximado hasta la inmediatez la información así como la posibilidad y facilidad de comunicación entre personas y grupos ha delineado los denominados derechos de participación. De este modo, los derechos humanos pueden genéricamente clasificarse en los siguientes órdenes: 1) derechos de protección: derecho a la vida, a la libertad, a la seguridad; 2) derechos de libertad: libertad de religión, de opinión y de asociación; 3) derechos sociales: dere-

15 «Todo lo referente a los derechos del hombre, más allá del viejo racionalismo que los deducía a partir de una determinada definición unitaria del concepto genérico de naturaleza humana, aparece hoy en la dimensión personal del hombre en cuanto individuo que se realiza de cara a un complejo de relaciones sociales. Este cambio de perspectiva incide no sólo en las diversas concepciones sobre el sujeto del derecho, sino que afecta también a los mismos contenidos del ordenamiento e incluso a las propias funciones del Estado. Sin embargo, aun reconociendo el gran valor y las potencialidades contenidas en esta nueva orientación, no puede olvidarse que por encima de las relaciones que constituyen formalmente al hombre como individuo en sociedad, existe en la persona una dimensión constitutiva esencial que la sitúa en una tesitura distinta del orden político y por encima del mismo Estado. Nos referimos directa y específicamente a aquellos aspectos y valores personales cuyo desarrollo y plenitud no pueden conseguirse ni a través, ni a partir del ejercicio positivo de los poderes públicos» (CALvo Espiga, A., «Acercamiento a la incidencia del derecho natural y de los derechos humanos en la elaboración del derecho», Scriptorium Victoriense 32, 1985, p. 307). 
cho al trabajo, alimentación, etc.; y 4) derechos de participación: derecho a tomar parte activa en la política y en la economía ${ }^{16}$.

La validez general de los derechos humanos, en relación con el desarrollo práctico de los ordenamientos democráticos, es principio necesario y punto de convergencia de todo planteamiento jurídico que prime la centralidad social y política de la persona a la hora de contrastar la estructura estatal con su único fin de servicio a la comunidad social ${ }^{17}$. Validez que entronca directamente con el proceso de su universalización acaecido, sobre todo, a partir del desarrollo que la teoría y práctica de los derechos humanos ha experimentado después de la segunda guerra mundial ${ }^{18}$. Universalización que, en el ámbito del derecho internacional, ha connotado una radical transformación del, durante siglos, denominado derecho de gentes en derecho del individuo, de cada uno de los individuos que, habiendo adquirido al menos potencialmente el derecho de demandar judicialmente al Estado, se van transformando en ciudadanos de un único Estado, en ciudadanos del mundo. Este que podríamos denominar como proceso de personalización de los derechos humanos también se manifiesta en la tendencia expansiva tanto cualitativa como cuantitativamente de estos

${ }^{16}$ «Como ha explicado Luigi Ferrajoli, los derechos universales de libertad -paradigmática pero no únicamente la libertad de pensamiento- deben ser considerados como «derechos a la diferencia» que implican lógicamente un deber, también universal, de tolerancia ante las diferentes identidades individuales; por su parte, los derechos sociales (yo también incluiría en esta misma categoría a los derechos políticos) tienen que interpretarse como derechos «a la igualdad» que implican el deber, sobre todo de parte de los poderes públicos, de tratar a cada individuo como una persona igual a las demás por lo que hace a las necesidades esenciales y a los intereses vitales. A partir de una concepción como ésta, fruto del momento más evolucionado del constitucionalismo, resulta justificada, o más bien obligatoria, la no-tolerancia -la intransigencia- frente a cualquier lesión a los derechos fundamentales» (Bovero, M., «La intransigencia en el tiempo de los derechos», Isonomía, n. 13, 2000, pp. 144-145). La mención a Ferrajoli se refiere a Ferrajoli, L., Diritto e ragione. Teoria del garantismo penale, Laterza, Roma-Bari, 1989, pp. 947-954.

${ }^{17}$ Un interesante planteamiento sobre la universalidad de los derechos humanos, tanto desde su fundamento como desde su proyección social y personal, puede verse en Hersch, J., Éclairer l'obscur. Entretiens avec G. et A. Dufour, L'Âge d'Homme, Lausanne, 1986, pp. 44-66; EADEM, «L'êthique: paradoxes de toujours et perversions d'aujourd'hui», en EADEM, L'exigence absolue de la liberté. Textes sur les droits humains (1973-1995), ed. por F. De Vecchi, Metis Presses, Ginebra, 2008, pp. 86-87; EADEM, «Quelques paradoxes des droits de l'homme», en EADEM, L'exigence absolue de la liberté..., cit., pp. 62-65; EADEM, «Les fondements des droits de l'homme dans la conscience individuelle», en EADEM, L'exigence absolue de la liberté..., cit., pp. 96-99; EADEM, «Les droits de l'homme d'un point de vue philosophique», en EADEM, L'exigence absolue de la liberté..., cit., pp. 104-110.

18 Cf. Cassese, A., I diritti umani oggi, Laterza, Roma-Bari, 2009, pp. 60-74. 
derechos ${ }^{19}$. Ahora bien, como ha sido puesto de relieve recientemente, si bien desde planteamientos distintos al que aquí hemos asumido, este proceso aparentemente favorecedor de una mayor centralidad de la persona en realidad la relativiza, pues «el Estado deja de ser un espacio de neutralidad, un lugar por encima de las pretensiones de cualquier absoluto o ideología y, por ello, con la única mira de tutelar la vida y la libertad de cada uno, así como su derecho de tener, cultivar y practicar (si así lo cree) un propio absoluto y una propia ideología... si se busca un modelo de esta perspectiva filosófico-jurídica total $-\mathrm{y}$, en este sentido, totalitaria-, también en este caso puede encontrarse en Mein Kamph.... ${ }^{20}$.

Así pues, la asunción sincera del valor universal de los derechos humanos, más allá de las ideologías subyacentes a los distintos regímenes políticos, es prueba inequívoca de que el ser humano, en su íntima estructuración personal, se conforma, desarrolla y perfecciona, es decir, construye su personalidad como identidad plural. En la medida en que esta realidad sea asumida por el ordenamiento como uno de los principios fundantes de su sello democrático, el sistema normativo deberá arbitrar ámbitos de libertad crítica para decidir social y jurídicamente sobre el valor e importancia que haya de atribuirse a las diferentes asociaciones, afiliaciones y opciones sociales, culturales y religiosas que enmarcan y condicionan las diversas y posibles pertenencias sociales en el marco social del ordenamiento ${ }^{21}$.

${ }^{19}$ Expansión o multiplicación de los derechos fundamentales que ha sobrepasado al propio ser humano como sujeto jurídico al considerar a los animales y a la propia naturaleza, en su sentido más amplio y genérico, como sujetos acreedores de derecho. Sin duda alguna, nos hallamos ante un proceso cuya novedad afecta a la propia teoría general del derecho tal como se ha consolidado a lo largo de los siglos. Al convertir en sujeto de derechos a individuos, especies o entes incapaces de responsabilidad se quiebra la relación derecho-deber o deber-derecho, eje fundamental de todo sistema jurídico y fundamento de las relaciones sociales. Al colocar al ser humano en un plano de igualdad, en cuanto a su dimensión de titular de derechos, con seres no humanos, no sólo se quiebra la relación deber-derecho, sino que la persona queda relegada a la periferia del derecho, convirtiendo al Estado o a los correspondientes órganos supraestatales en únicas fuentes fundantes y legitimadoras de los derechos fundamentales. La persona deja, en este supuesto, de ser raíz, origen y fundamento del derecho. Ni siquiera las relaciones sociales interpersonales conformadas en la dialéctica deber-derecho se consideran razón suficiente de la norma, como formalmente acaeciera ya desde el derecho romano. Sólo el aparato del Estado y su fuerza coactiva se erigen en creadores de normas (legislador) y en única fuente de derecho (iuris-dador), al margen de la persona y más allá y por encima de la propia sociedad.

20 Escobar, R., La paura del laico, Il Mulino, Bolonia, 2010, p. 46.

${ }^{21}$ Cf. Calvo Espiga, A., «Identidad y pertenencia: ordenamiento jurídico y pluralismo religioso», en Centro de Estudios Andaluces (ed.), El fenómeno religioso. Presencia de la Religión y la religiosidad en las sociedades avanzadas. II Jornadas de Sociología. Sevilla, 13-14 de junio 2007:

http://www.centrodeestudiosandaluces.info/cursos/adjuntos/1211182.pdf 
Sobre todo a partir del último tercio del siglo pasado, se viene constatando un interesante fenómeno socio-político. Me refiero a la frecuencia con que se invocan los derechos humanos como inequívoco contraste de denuncia frente a las distintas situaciones de opresión y violencia que se verifican en ordenamientos jurídicos y prácticas políticas ${ }^{22}$. Sin embargo, esta situación de aparente sensibilidad respecto a la centralidad de los derechos de la persona, hasta el extremo de haber sido considerados como un auténtico ethos mundial, difícilmente se compadece con la parcialización y reduccionismo con que la mayoría de los ordenamientos integran en su desarrollo social y normativo la cuestión de los derechos humanos ${ }^{23}$. Pues,

22 A pesar de los muchos y variados pronunciamientos en torno a la necesaria relación entre democracia, Estado de derecho y respeto a los derechos humanos, éstos no pasan de ser, en la mayoría de los casos, libertades meramente formales. Incluso no faltan quienes no aceptan verdadero rigor jurídico en la propia conceptualización de la misma fórmula derechos humanos, al considerarla, en el mejor de los casos, mera coartada política o un cómodo salir del paso cuando en una sociedad pierden relevancia e influencia la fe religiosa, el pensamiento filosófico o el orden jurídico. En esta línea se manifestaba, por ejemplo, R. Wiethölter en su Rechtwissenschaft, publicada en Frankfurt el año 1968, sobre todo en los capítulos tercero y cuarto de esta obra en los que trata, respectivamente, de los derechos naturales y de la imagen/relación hombre-derecho. Insiste este autor en la posible falacia que puede ocultarse tras ciertas invocaciones a los derechos humanos fundadas en una discutible pre-comprensión clasicista determinada, a su vez, por un cierto estatismo esencialista frente a una aceptación de la diversidad de concreciones históricas, del derecho natural. También puede resultar útil para la comprensión de esta problemática, aun cuando su objetivo inmediato tenga que ver directamente con las implicaciones del derecho natural y la moral, un breve artículo de J. Fuchs titulado «Diritto naturale o fallacia naturalistica?», Rassegna di Teologia 29, 1988, pp. 313-337.

23 «Nel discorso Le fondement théologique des droits de l'homme, tenuto nel novembre 1988, il vescovo di Roltenburg-Stuttgart, Walter Kasper, ha scritto una frase che può costituire la conclusione del mio discorso: «I diritti dell'uomo costituiscono al giorno d'oggi un nuovo ethos mondiale». Naturalmente, occorre non dimenticare che un ethos rappresenta il mondo del dover essere. Il mondo dell'essere ci offre purtroppo uno spettacolo molto diverso. Alla lungimirante consapevolezza circa la centralità di una politica tesa alla sempre migliore formulazione e alla sempre migliore protezione dei diritti dell'uomo corrisponde la loro sistematica violazione in quasi tutti i paesi del mondo, nei rapporti tra un paese e l'altro, tra una razza e l'altra, tra potenti e deboli, tra ricchi e poveri, tra maggioranze e minoranze, tra violenti e rassegnati. L'ethos dei diritti dell'uomo splende nelle solenni dichiarazioni che restano quasi sempre, e quasi dappertutto, lettera morta. La volontà di potenza ha dominato e continua a dominare il corso della storia. L'unica ragione di speranza è che la storia conosce i tempi lunghi e i tempi brevi. La storia dei diritti dell'uomo, meglio non farsi illusioni, è quella dei tempi lunghi. Del resto, è sempre accaduto che mentre i profeti di sventure annunciano la sciagatura che sta per avvenire e invitano a essere vigilanti, i profeti dei tempi felici guardano lontano... $\mathrm{Ci}$ sarebbe da stare poco allegri se non fosse che un grande ideale come quello dei diritti dell'uomo rovescia completamente il senso del tempo, perché si proietta nei tempi lunghi, come ogni ideale, il cui avvento non può essere oggetto di una previsione, come 
siguen siendo habituales las continuas rupturas de la observancia y respeto de los derechos del hombre en el seno de la comunidad internacional incluso por aquellos Estados que, al menos teóricamente, al interior de sus particulares organizaciones nacionales presumen de ser celoso guardianes de los derechos humanos ${ }^{24}$. Y no sólo en el ámbito internacional, también en el seno de comunidades políticas social e ideológicamente satisfechas de sus actitudes observantes de los derechos humanos se detectan con gran frecuencia situaciones en que por razones de conveniencia política, o por efectividad económica o bien por cuestiones de orden público, se violan sin pudor alguno, e incluso con el aplauso de la masa indolentemente acomodada, derechos personales básicos; o bien se les mantiene en una situación tal que, aun cuando formalmente reconocidos, su ejercicio real y jurídicamente efectivo resulta imposible para gran parte de los ciudadanos ${ }^{25}$.

Pero no por ello deja de ser cierto el hecho incontestable de que la violación de los derechos humanos legitima la descalificación, como carente de verdadera y auténtica o legítima autoridad, de aquellos regímenes sociales o políticos que, de un modo u otro, desconozcan el protagonismo de los derechos fundamentales de sus ciudadanos. La razón que fundamenta esta descalificación no es primaria ni principalmente de orden político, sino que se trata, aun cuando no se pretenda directamente, de una reflexión de carácter ético o moral orientada desde principios elementales que se fundamentan en y derivan del propio ser humano. Precisamente por no tratarse de un razonamiento político, sino de un postulado ético o moral previo a cualquier forma o ejercicio del poder político, cabe la crítica y rebelión desobediente, tanto desde el propio sistema jurídico-político como desde fuera de sus coordenadas, ante las legalmente sutiles o dictatorialmente burdas violaciones o desprotección de los derechos del hombre. Crítica y rebelión cuya legitimación

dicevo all'inizio, ma soltanto da un presagio» (BoBbio, N., L'eta dei diritti, Giulio Einaudi, Turín, $1997^{3}$, pp. 264 y 266).

24 «Nell'epoca contemporanea, tra i vari segni dei tempi non può passare in secondo piano la crescente attenzione che in ogni parte del mondo è rivolta ai diritti dell'uomo, sia per la coscienza sempre più sensibile e profonda che si forma nei singoli e nella comunità intorno a tali diritti, sia per il continuo doloroso moltiplicarsi delle violazioni contro di essi» (Pontificia Commissio Iustitia et Pax, La Chiesa e i diritti dell'uomo, §1, Editrice Vaticana, Città del Vaticano, 1975, p. 1).

${ }^{25}$ «In un discorso generale sui diritti dell'uomo occorre per prima cosa tenere distinta la teoria dalla prassi, o meglio rendersi subito conto che teoria e prassi camminano su due binari distinti e a velocità molto diverse. Voglio dire che dei diritti dell'uomo si è parlato e si continua a parlare in questi anni tra uomini di studio, filosofi, giuristi, sociologi e uomini politici, molto di più di quel che si sia riusciti sinora a fare per riconoscerli e proteggerli effettivamente, cioè per trasformare aspirazioni, nobili ma vaghe, richieste giuste ma deboli, in diritti in senso proprio (nel senso cioè in cui parlano di «diritto» i giuristi)» (BobBio, N., L'età dei diritti ..., cit., p. 66). 
sería imposible desde una concepción meramente positivista y voluntarista de la producción de la norma por parte del poder político.

\subsection{Razón y razonabilidad como lugares hermenéuticos.}

La racionalidad constituye el segundo rail o referente hermenéutico en que se articula esta exposición. Me refiero de forma mediata a la racionalidad entendida, sobre todo, en el sentido asumido por los juristas romanos cuando se referían a la naturaleza y funciones tanto del ius naturale como del ius civile, pues lo mismo en el caso del ius civile que en el del ius gentium se verifica una determinación positiva de los elementos de equidad y racionalidad presentes en ambos derechos. Y, aunque en algunos casos existieran en el ordenamiento positivo normas concretas que no se fundamentasen en la ratio naturalis, ni siquiera en la aequitas, sin embargo, tanto la una como la otra, bien de forma directa, cuando son asumidas o, por el contrario, de manera indirecta en cuanto elemento crítico, cuando rechazadas por el derecho positivo, constituyen el verdadero ius naturale ${ }^{26}$.

Para los Romanos, pues, la ratio, en cuanto elemento presente tanto en la lex como en el ius, no se reduce a algo meramente formal sino que remite a un elemento substancial en cuanto que lex y ius han de tender a producir una auténtica igualdad entre los ciudadanos que, en última instancia, se traduce en justicia. La ratio se concreta en la objetivación racional de la norma en referencia necesaria a una realidad concreta de existencia personal y convivencia social. Una ley, por tanto, desprovista de ratio, en la que sólo prevaleciera el imperio positivista de la voluntas del legislador no sería propiamente lex al no comportar en si misma verdadero ius ni, por tanto, verdadera juridicidad. Y ello aun en el caso en que la voluntad del legislador, actuada incluso por medios coactivos, obligara a su cumplimiento. Otro tanto puede decirse de los juristas medievales que continuamente buscan, una veces de forma explícita y otras como marco o telón de fondo de sus reflexiones, la armonización entre auctoritas y ratio que, en esta época, quizás se debiera calificar mejor de rationabilitas que de ratio, sobre todo, por la pretensión de conseguir o realizar la aequitas a través de la norma y de su aplicación ${ }^{27}$.

Se trata, pues, de la racionalidad que se presenta como constitutivo necesario del derecho, en cuanto que éste es el único instrumento de carácter personal con dimensión social capaz de mantener e integrar la necesaria relación entre sociedad y poder político del Estado dentro de unos límites con capacidad para impedir la negación y absorción de lo humano-social en el ámbito estrictamente político. Racionalidad, en definitiva, no en el sentido del individualista y solipsista cogito ergo sum; sino en el del personal, exis-

${ }^{26}$ Cf. D 1, 1, 11; 1, 2, 1; CiCerón, De natura deorum 2, 62, 3; IDEM, Topica 2, 9.

${ }^{27}$ Cf. Calvo Espiga, A., «Sobre el método en el estudio del Derecho Civil: una aproximación a la Historia», Anuario de Derecho Civil, LVIII/IV, 2005, pp. 1604-1611. 
tencial y abierto radicalmente a una íntima e ineludible relación con todo lo que existe cogito quia sum.

Es decir, nos hallamos ante lo que podríamos determinar como racionalidad crítica, que necesariamente está implicada y supuesta en toda actitud pluralista, por tratarse de aquella que se ejerce y actúa cuando se vive en la posibilidad personal, social y política de optar por pertenencias libres y, consecuentemente, responsables, resultado de una elección sin predeterminaciones o imposiciones. Por el contrario, las pertenencias personales se convierten en irracionales cuando las relaciones humanas, tanto las personales como las sociales y políticas, entre individuos que puedan sentirse distintos respecto a sus identidades personales y sociales, quedan reducidas primariamente a términos de descomprometida coexistencia, fútil amistad o vacuas, por altisonantes, alianzas, sean de pueblos, civilizaciones o culturas; $\mathrm{o}$, incluso, a bienintencionados diálogos entre poderes públicos y grupos religiosos que nunca llegan a plantear la radicalidad de sus diferencias.

La irracionalidad acrítica, actitud que imposibilita el pluralismo, bien como actitud personal ya como hecho o valor social, en las pertenencias sociales suele desvelarse, sutil en apariencia pero patológica en sus consecuencias, cuando ante las opciones y posturas que diversifican y enriquecen el mundo se intenta su uniformidad mediante clasificaciones dominantes o descalificaciones exclusivas y excluyentes, tanto desde la pertenencia religiosa como desde la cultural, étnica, de creencias o de civilización: según convenga, se unilateraliza cualquiera de estos factores como el único determinante o causante de los grandes conflictos a que se enfrenta nuestra sociedad. De este modo se criminaliza y excluye al otro, a lo otro, a lo extraño, al tiempo que se desarrollan mecanismos de miedo al distinto en cuanto peligro desconocido y total, consolidando como fundamento de estructuración social la irracionalidad consecuencia irremediable del miedo.

Constituye, por ejemplo, muestra de incongruente irracionalidad la actitud de quienes consideran la pertenencia religiosa como factor o elemento generador de conflictividad social. La irracionalidad acrítica radica, en este caso, en el hecho de que, habitualmente, quienes atribuyen a la pertenencia religiosa este efecto disgregador y negativo respecto a la convivencia social suelen negar, al mismo tiempo y por principio, le dimensión pública de la religión, reduciéndola a los sótanos del más privado individualismo espiritualista y privando simultáneamente a la persona de una de sus más fundamentales relaciones de pertenencia. Por el contrario, la pertenencia personal racional y razonadamente crítica parte siempre del irrenunciable supuesto o principio de que la sociedad es un espacio abierto a una variada pluralidad de identidades personales, así como del hecho de que todas ellas se entrecruzan hasta la perplejidad de conformar sociedades libres y en activa apertura, en permanente encrucijada, sin el menor atisbo de uniformidad. Aun cuando se intente aparentar lo contrario, la uniformidad social, en lugar de reducir- 
las o anularlas, aumenta y profundiza las rupturas y divisiones con que las ideologías y creencias excluyentes amenazan al pluralismo social.

Espero, pues, que la racionalidad y razonabilidad, abiertas a la búsqueda de la verdad y al reconocimiento del error, jalonen los carriles hermenéuticos entre los que discurra mi exposición, siempre en el horizonte metodológico del pluralismo y desde los límites delineados por los derechos humanos: pluralismo y derechos humanos conforman, pues, el entorno y perspectiva principales desde los que se han de valorar las ideas que someto al crítico discernimiento del benévolo lector.

\section{ACERCAMIENTO AL ENTORNO HISTÓRICO-JURÍDICO.}

Desde una perspectiva jurídica o institucional, las relaciones entre el Estado y las comunidades religiosas como entes institucionales distintos del Estado comienzan propiamente con el nacimiento del Imperio cristiano (s. IV-V). Hasta ese momento, dada la situación jurídica del Cristianismo, los cristianos se sometían sin más, en todos los órdenes de la vida, al poder imperial siempre que las decisiones del emperador o de otras instancias políticas no se opusieran a la voluntad de $\operatorname{Dios}^{28}$. Las primeras comunidades cristianas, pues, aceptaron e incluso utilizaban las fórmulas jurídicas del derecho corporativo romano para determinar y definir su situación jurídica en la sociedad, siempre que la competencia jurídica del Estado o su poder político no se presentara con un grado tal de omnipotencia que llegara a convertirse en una absolutización, incluso religiosa, de la propia estructura imperial.

Con la declaración del Cristianismo como religión oficial del Imperio y la evangelización general de los dominios de Roma surgió un tipo peculiar de sociedad fundada en el entramado de Iglesia e Imperio que, a lo largo de la historia, ha sido denominada con distintos apelativos: cristiandad, régimen de sacralidad, teocrático o hierocrático. Sin embargo, las propias injerencias que surgen como consecuencia de la relación de amistad en que se habían encauzado las relaciones entre la Iglesia y el Imperio darán origen a las primeras discrepancias entre ambas instituciones. El año 356, Osio, obispo de Córdoba, fue requerido por el emperador Constancio II para que emitiera

${ }^{28}$ «Ahora bien, esto no significa que desde el mismo momento fundacional-apostólico no se exigiera a los cristianos una vida en correspondencia evangélica y ciudadana con el mundo, sin que ello supusiera en ningún momento por parte de los cristianos un intento reflejo y directo de imposición, revolucionaria o legitimadora, de su concepción cristiana de la vida al ordenamiento jurídico del Estado: se respeta, pues, al Estado y, consecuentemente, se admite en principio su ordenamiento de la vida social» (CALvo EsPIGA, A., Implicaciones jurídico-canónicas de la relación entre la Iglesia y la Comunidad Politica. Sobre el derecho de los pastores de la Iglesia para intervenir magisterialmente en asuntos políticos, Eset, Vitoria, 1984, p. 20). Puede verse RAHnER, H., Kirche und Staat im frühen Christentum (Dokumente aus acht Jahrhunderten und ihre Deutung), Kösel-Verlag KG, Munich 1961, pp. 19-79. 
condena sobre San Atanasio e indirectamente sobre la fe profesada en Nicea. La iniciativa imperial iba dirigida a un asunto que afectaba al meollo mismo de la formulación de la fe. Desde la serenidad de sus cien años, templada en la persecución desatada por Maximiano, abuelo del propio Constancio, y probada en la estrecha colaboración con su padre Constantino, el Grande, Osio, tratándole más como a un hijo que como a un emperador, escribe a Constancio, a partir de la clara proclamación del dualismo cristiano:

«No te inmiscuyas en las cuestiones eclesiásticas, ni pretendas mandarnos en ellas: más bien, debes aprenderlas de nosotros. A Ti Dios te entregó el Imperio y a nosotros lo eclesiástico. Y, así como quien te arrebata el imperio va contra la ordenación divina, así también podrías hacerte reo de un gran crimen si acapararas lo eclesiástico. Porque está escrito: Dad al César lo que es del César y a Dios lo que es de Dios (Mt 22, 21). Por consiguiente, ni a nosotros nos está permitido mandar a la tierra, ni tú tienes poder sacerdotal $»^{29}$.

Discrepancias u oposición que, iniciadas en el mismo siglo del Edicto de Milán, fueron mantenidas y defendidas por los pontífices romanos del siglo $\mathrm{V}$ y de forma relevante por el papa San Gelasio (492-496) quien, por vez primera, describe doctrinalmente los términos de esta polémica mediante la teoría de los dos poderes, en la que se describen, acotan y comparan las atribuciones de ambas potestades, constituyendo la primera formulación y fundamentación doctrinal del denominado dualismo cristiano:

«Dos son, Emperador augusto, los poderes por los que principalmente se gobierna este mundo: la autoridad sagrada de los Pontífices y la potestad real... Ten en cuenta, hijo clementísimo, que aunque presidas al género humano, sin embargo, has de someterte devotamente a quienes administran los asuntos divinos $»^{30}$.

Polémica que, a lo largo de la Edad Media, viene determinada por la tensión existente entre el intento de convertir a la Iglesia en una parte más, aunque principal, de la estructura del poder político y la resistencia de la Iglesia por conseguir un reconocimiento social efectivo de su independencia, e incluso de superioridad en algunos asuntos, respecto a los príncipes seculares, acudiendo para ello a la conocida imagen de las dos espadas.

${ }^{29}$ «Ne te rebus misceas ecclesiasticis, neu nobis his de rebus praecepta mandes: sed a nobis potius haec ediscas. Tibi Deus Imperium tradidit, nobis eclesiastica concredidit. Ac quemadmodum qui tibi Imperium subripit Dei ordinationi repugnat, ita metue ne si ad te eclesiastica pertrahas magni criminis reus fias. Reddite, scriptum est, quae sunt Caesaris Caesari et quae sunt Dei Deo (Mt 22, 21). Neque nobis igitur terrea imperare licet, neque tu imperator adolendi habes potestatem» (PL, t. 8, col. $1329 \mathrm{C}$ ).

30 «Duo quippe sunt, imperator auguste, quipus principaliter mundus hic regitur: auctoritas sacrata Pontificum et regalis potestas... Nosti enim, fili clementissime, quod licet praesideas humano generi dignitate, rerum tamen praesulibus divinarum devotus colla submittis...» (PL 59, col. 42). 
Dualismo que, tras las vicisitudes y controversias entre partidarios de las distintas supremacías a lo largo de toda la Edad Media, todavía resonaba con íntima armonía en la dedicatoria de su Catecismo que Bartolomé de Carranza ofrecía a Felipe II:

«En dos partes distribuyó Cristo Nuestro Señor el gobierno del mundo, la una espiritual y la otra temporal, conforme a las partes del hombre, que son ánima y cuerpo. Como entre las partes del hombre hay tanta amistad que, aun después de apartada por la muerte, les queda muy grande apetito de tornarse a juntar, el cual se cumplirá universalmente el día del juicio, así estas dos partes de gobierno, espiritual y temporal, quieren estar tan unidas y conformes que cada una ha de tener cuidado de entrambas, para que el cuerpo y compañía humana esté siempre animada como conviene» ${ }^{31}$.

Con los altibajos que sufrió la compleja relación de fuerzas en torno al mundo eclesial y político de la Edad Media, a las puertas de la Reforma protestante, no se había conseguido armonizar la profunda dicotomía que separaba a partidarios del poder regio de los que defendían la preeminencia del papado sobre el rey. Cierto que hubo personas y momentos en que, al menos circunstancialmente, se impuso la moderación, si bien no llegó a encontrarse el criterio o modo de actuación que aunase el ejercicio justo y equitativo de las dos espadas ${ }^{32}$. El modelo de Estado que se configura a lo largo del Renacimiento tampoco ayudó mucho en esta tarea, al tender, dada su configuración política y como consecuencia de la maduración del centrífugo proceso nacionalista iniciado en Europa en la Edad Media, a la unificación y concentración de toda la jurisdicción en la persona del monar$\mathrm{ca}^{33}$. Los gobernantes del Renacimiento centralizan en sus personas todos los poderes del Estado, apoyados, sobre todo, en las teorías que defendían que la soberanía del rey no era más que la encarnación de la soberanía del Estado. Si bien, en principio, los gobernantes asumían la independencia y el

31 Bartolomé de Carranza, Comentarios sobre el Catechismo christiano (Amberes 1558), editado por J. I. Tellechea Idígoras, vol. I, Biblioteca de Autores Cristianos, Madrid, 1972, p. 103.

32 Cf. Clercq, Ch. de, «Charlemagne, législateur chrétien», Revue de Droit Canonique 2, 1952, pp. 352-485; FernÁNDEZ CONDE, F. J., «El «agustinismo político» y su importancia en la evolución histórica del Medioevo», Burgense 13, 1972, pp. 458-487; García Villoslada, R., «La idea de Sacro-Romano Imperio según Suárez», Razón y Fe 138, 1948, pp. 285-311; ReInA, V., «Los términos de la polémica Sacerdocio-Reino», Ius Canonicum 6, 1966, pp. 153-199; Rousset, P., «La notion de Chrétienté aux XI ${ }^{\mathrm{e}}$ et XII siècles», Le Moyen Age 69, 1963, pp. 191-203; STICKLER, A. M., «Il Gladius nel Registro di Gregorio VII», Studi Gregoriani 3, 1948, pp. 89-103; IDEM, «Il Gladius negli Atti dei Concili e dei RR Pontefici sino a Graziano e Bernardo di Clairvaux», Salesianum 13, 1951, pp. 414-445; Lanseros, M., «El Derecho y el Estado en San Agustín», Revista Española de Derecho Canónico 1, 1946, pp. 521-530.

${ }_{33}$ Cf. Calvo Espiga, A., «Sobre el método en el estudio del Derecho Civil...»..., cit., pp. 1623-1624. 
protagonismo social de la Iglesia, poco a poco intentan someter lo eclesial a lo político mediante la integración de la Iglesia en los esquemas jurídicopolíticos de los nuevos Estado absolutos, de manera que, en algunos casos, la autoridad política intervenía directamente en cuestiones que afectaban a la propia estructura jurídica fundamental de la Iglesia ${ }^{34}$. La incidencia que las concepciones políticas renacentistas tuvieron en el cambio de actitud de las monarquías europeas respecto a la Iglesia, se vio, en cierto modo, reforzada por el impacto que en la Iglesia y la sociedad europea tuvieron los postulados eclesiales y políticos de la Reforma protestante.

A partir de este momento, al menos en el ámbito europeo, se asiste a un proceso continuado de absolutización del Estado, proceso que, como es lógico, afecta a las relaciones entre el Estado y el Cristianismo que deja de manifestarse en Europa de forma unitaria. Sin embargo, sería erróneo generalizar el status de la Iglesia en los distintos Estados europeos: la situación real de la Iglesia variaba mucho de unos países a otros dependiendo, sobre todo, del grado de anticlericalismo y sectarismo ideológico de las distintas tendencias liberales que llegaron a prevalecer en los distintos Estados. La consolidación de las democracias occidentales durante el siglo XX junto a las nuevas opciones y actitudes doctrinales asumidas por la Iglesia han propiciado un sistema de relación de los poderes públicos con la Iglesia Católica, con las demás Confesiones Religiosas y con el propio fenómeno religioso que, lejos de los viejos esquemas de poder en que se fundamentaron históricamente, se articula a partir del reconocimiento del derecho de libertad religiosa como uno de los quicios del Estado de derecho ${ }^{35}$.

\section{EL ESTADO DE DERECHO COMO LUGAR JURÍDICO.}

¿Qué entiendo en esta sede por Estado de derecho? Expresión, por otra parte, tan tópica en nuestra sociedad, por lo abundante de su uso, que ha lle-

${ }^{34}$ Cf. Giacchi, O., Lo Stato laico, Vita e Pensiero, Milán, 1978, pp. 13-29; Rouco Varela, A. M., Staat und Kirche im Spanien des 16. Jahrhunderts, Max Hueber, Munich, 1965, pp. 150-188 y 211-219.

${ }_{35}$ Cf. Aldea Vaquero, Q., «España, el Papado y el Imperio durante la Guerra de los Treinta Años, I. Instrucciones a los embajadores de España en Roma (1631-1643)», Miscelánea Comillas 16, 1958, pp. 291-437; IDEM, «España, el Papado y el Imperio durante la Guerra de los Treinta Años, II. Instrucciones a los Nuncios Apostólicos en España (1624-1632)», Miscelánea Comillas 16, 1958, pp. 249-330; IDEM, «Iglesia y Estado en la España del siglo XVII (Ideario político-eclesiástico)», Miscelánea Comillas 19, 1961, pp. 143-354; AtKinson, J., Lutero y el nacimiento del protestantismo, Alianza, Madrid, 1971, pp. 269-280 y 310; Alonso NiÑo, S., El pensamiento regalista de Francisco Salgado de Somoza (1595-1665). Contribución a la historia del regalismo español, CSIC, Salamanca, 1973, pp. 41-66; Courvoisier, J., De la Réforme au Protestantisme, Beauchesne, Paris, 1977, pp. 23-25 y 87-88; García Villoslada, R., Raíces históricas del luteranismo, Biblioteca de Autores Cristianos, Madrid, 1976, pp. 179-200; Gorricho Moreno, J., «Iglesia y Estado en tiempos de Felipe IV (1621-1665)», Scriptorium Vic- 
gado a vaciarse de contenido al dar por supuesto que todo el mundo conoce su significado cuando, de hecho y de derecho, pocas personas están verdaderamente al tanto del arcano de sus implicaciones y consecuencias.

\subsection{El Estado, concepto jurídico-político y realidad social.}

Aunque pueda, sin temor a equivocación, afirmarse que en todas las épocas han existido formas estatales de gobierno, en el sentido de sistemas políticos organizados, parece ser mérito de Maquiavelo la fijación de lo que podría considerarse como una primera definición de Estado, en sentido moderno, cuando en la primera frase del capítulo primero del Príncipe (1513) afirma: «tutti gli stati, tutti e' dominii che hanno avuto e hanno imperio su li uomini, sono stati e sono o repubbliche o principati».

Con anterioridad, el término Estado no comportaba ningún sentido específico en relación con la organización de la gestión pública del gobierno en la sociedad. En Roma, por ejemplo, el término status se utilizaba para designar la condición jurídica de pertenencia a una determinada colectivi$\mathrm{dad}^{36}$, pues para referirse a lo que hoy entendemos por Estado utilizaban los términos Civitas o Res Publica. Durante la Edad Media, el término Estado se solía aplicar a las ciudades libres, independientes de cualquier poder ajeno a ellas: así se podía hablar, por ejemplo, del Estado de Florencia o de la ciudad de Venecia. A partir del siglo XVI, se ha venido entendiendo por Estado el entramado institucional en el que se da un poder de imperio o dominio sobre las personas que habitan en un determinado territorio.

Partiré en esta exposición de lo que se podría considerar como una definición descriptiva, y en principio lo más aséptica posible, del topos Estado, teniendo siempre muy presente que definir es equivalente a limitar. Si bien es cierto que la limitación implicada en toda definición resulta necesaria en orden a fijar los términos de la exposición y las condiciones y características de los argumentos que en ella se vayan a utilizar. Dado, pues, el carácter de este análisis ha de quedar patente que, como sucede en toda definición, también aquí, desde la opción hermenéutica por la que hemos optado, opera desde el inicio una especie de juicio en razón del cual, aun cuando esté abierto a revisión, se pueden proponer hipótesis así como validar tesis. En la medida en que, al definir, se configura esencialmente un dominio, se está simultáneamente expresando el entorno de un conjunto homogéneo de relaciones. La definición, pues, en el sentido en que la asumimos en esta sede, más que agotar el significado de lo definido, muestra o delimita el perímetro en que lo definido se desenvuelve. La definición, pues, y en este caso

toriense 49, 2002, pp. 241-269; Rouco VARELA, A. M., «Antecedentes históricos de las relaciones actuales entre la Iglesia y la Comunidad Política de España», Salmanticensis 21, 1974, pp. 217-234.

36 Cf. Calvo Espiga, A., «Para una aproximación al tópico «derechos humanos»»», Lumen 43, 1994, pp. 90-96. 
de forma relevante, es una limitación necesaria, tanto por lo que se refiere al contenido objetivo de lo definido, cuanto por lo que afecta a la forma o método argumentativo que, de algún modo, queda determinado en y por la propia definición ${ }^{37}$. Lo hasta aquí dicho, propio de toda definición, adquiere, como ya se ha apuntado, pleno sentido cuando se aplica a cualquier intento de definir el Estado de derecho. Entenderemos, pues, por tal la organización de la vida colectiva de un grupo social complejo y de carácter secundario en un territorio concreto según unos determinados fines para cuya consecución se dispone de la exclusividad del poder coactivo. A partir de esta definición o descripción, cabría enumerar como fundamentales e insustituibles los siguientes elementos constitutivos del Estado:

a) La existencia de un grupo social establecido sobre un determinado territorio que, por la complejidad de sus relaciones, sobrepasa el marco de las relaciones comunitarias o primarias.

b) La presencia de un conjunto de normas escritas o no, sean de carácter usual o consuetudinario, que regulan y ordenan las instituciones fundamentales, en cuanto que esas instituciones permiten y facilitan al grupo el desarrollo de una vida ordenada y, a su vez, disciplinan y encauzan el ejercicio de los poderes superiores de decisión y mando.

c) El ejercicio del poder coactivo, que implica el derecho exclusivo de la institución estatal, frente a los demás miembros del grupo, de recurrir en última instancia a la fuerza para mantener el orden interno de su sociedad y territorio o bien para repeler cualquier intromisión o ataque provenientes del exterior.

d) La exclusividad del Estado en el uso del ejercicio legítimo de la violencia exige y supone que sólo en casos excepcionales, netamente tasados y rigurosa y estrictamente previstos, son autorizados los miembros del grupo a utilizar individualmente la fuerza.

Soberanía e independencia, como ya planteara el propio Aristóteles ${ }^{38}$, han sido consideradas clásicamente, sobre todo desde la Teoría del Estado

37 «Una de las técnicas esenciales de la argumentación cuasi lógica es la identificación de diversos elementos que son objeto del discurso. Todo uso de conceptos, toda aplicación de una clasificación, todo recurso a la inducción implica una reducción de ciertos elementos a lo que hay en ellos de idéntico o intercambiable; pero sólo calificaremos esta reducción de cuasi lógica cuando esta identificación de seres, de acontecimientos o de conceptos no sea considerada del todo arbitraria ni evidente, es decir, cuando dé o pueda dar lugar a una justificación argumentativa...

«El procedimiento más característico de identificación completa consiste en el uso de definiciones. Cuando éstas no formen parte de un sistema formal, incluso aunque pretendiesen identificar el definiens con el definiendum, las consideraremos casos de argumentación cuasi lógica» (Perelman, Ch. y Olbrechts-Tyteca, L., Tratado de la argumentación. La nueva retórica, § 50, tr. J. Sevilla Múñoz, Gredos, Madrid, 1989, p. 328).

${ }^{38}$ Véase, por ejemplo, Pol. III, 1278b, 8-17 y Pol. IV, 1295b, 1. 
de Jean Bodin (1530-1596), como características típicas y necesarias de la especificidad del Estado frente a cualquier otra forma de organismo o agregado social. Se suele considerar la soberanía como el elemento específicamente distintivo del ordenamiento estatal respecto a los de cualquier otra forma de asociación humana. Precisamente el reconocimiento y atribución de soberanía a los Estados nacionales señala el momento en que se rompió el orden medieval. Se considera, pues, soberano a todo poder que no está sujeto ni a la autoridad externa del Imperio y de la Iglesia, ni está obligado a compartir la propia soberanía con otros centros de poder existentes en la misma sociedad, como era, por ejemplo, el caso de las corporaciones medievales ${ }^{39}$. Nos hallamos, pues, ante la propiedad o característica que tiene el Estado de ser titular de un poder que no deriva de ningún poder superior y que, a su vez, es fuente constitutiva de poderes inferiores. Desde una perspectiva netamente jurídica, el Estado se reconoce como fuente de ordenamientos originarios mientras que los restantes poderes o instituciones, al margen de su relevancia social o política, sólo fundamentarían ordenamientos derivados. Naturalmente relacionada con la soberanía, se suele entender la independencia como la capacidad del propio Estado de determinarse autónomamente en sus relaciones con otros Estados en plano de igualdad jurídica.

Desde el siglo XVI la historia de la afirmación de la soberanía ha corrido pareja a la conformación del Estado moderno, epígono de las características apuntadas. Ello, sin embargo, no obsta al hecho de que ya en este mismo siglo se iniciara un proceso que desemboca en el absolutismo del siglo $\mathrm{XVIII}^{40}$ y que, a posteriori, originó la crisis del Estado moderno fraguada a principios del siglo XX. Proceso que, de forma eminente, se concreta por una parte en el distanciamiento que se produce entre Estado y sociedad, generando una progresiva y sorda separación entre lo que se ha denominado Estado-aparato y Estado-comunidad y, por otra, en la creciente dificultad de hacer efectiva una auténtica y armónica separación de poderes, determinada en buena medida por la preeminencia y exagerado protagonismo que, sobre todo a partir de la segunda gran guerra, han asumido los partidos políticos y sus propios intereses partidistas en detrimento de las necesidades y urgencias de los ciudadanos. Crisis que propició la emergencia de una nueva formulación o caracterización jurídico-política a fin de reforzar la dimensión social y democrática del Estado: me refiero a la categoría Estado de derecho.

\subsection{El Estado de derecho, legitimación jurídica de la estructura estatal.}

Al menos en su conformación o formulación inicial, el Estado de derecho se caracterizaba por la atribución a la norma jurídica general, especialmente a las leyes, dadas sus propiedades de generalidad y abstracción, de

${ }^{39}$ Cf. Calvo Espiga, A., «Sobre el método en el estudio del Derecho Civil...», cit., pp. 1604-1611.

${ }^{40}$ Cf. Meyer, J., Le despotisme éclairé, PUF, Paris, 1991, pp. 5-21 y 92-123. 
un protagonismo e incidencia fundamentales en la vida social delimitada y determinada por el ordenamiento. Situación que, desde la perspectiva del ciudadano, legitimaba la comprensión del Estado de derecho como aquel en que todos son iguales ante la ley y, sobre todo, en que la ley es igual para todos ${ }^{41}$. Ello significa que, desde su dimensión o perspectiva institucional, en el Estado de derecho todos los poderes, incluido el legislativo, son determinados, regulados y limitados por el derecho, es decir, están sometidos al imperio de la ley. Dos han sido los principales medios o recursos que se han utilizado para evitar que el legislador transforme su independencia en tiranía promulgando leyes a medida de personas o intereses: la idea ético-política de un límite pre-normativo conformado por los derechos naturales de la persona, frontera que de ningún modo podría traspasar el legislador, dada su radicación en el propio orden natural o en un inicial pacto social en el que se fundamenta y sobre el que se articula el Estado; y, desde el ámbito del derecho positivo, por la presencia de una norma suprema o supra-normativa que vincula al propio legislador ordinario y a todos los demás poderes del Estado: la existencia de una Constitución rígida.

Además de estos límites, los Estados contemporáneos han arbitrado otra serie de medios jurídicos a fin de garantizar institucionalmente no sólo el ideal, sino también, y sobre todo, la concreta efectividad y operatividad del Estado de derecho. Me refiero a la separación controlada de los poderes básicos y fundamentales del Estado: legislativo, ejecutivo y judicial; a la diferenciación institucional y competencial de los órganos capacitados para crear leyes de aquellos que únicamente tienen la función de aplicarlas; a la confianza y respaldo políticos e institucionales del poder ejecutivo (Gobierno) por parte del legislativo (Parlamento); a la independencia real de los jueces, no sólo en lo que se refiere o afecta al momento crucial en que el magistrado se enfrenta en la soledad de su ciencia y conciencia al acto de sentenciar, sino también y sobre todo en lo que afecta a la organización y gobernanza del propio poder judicial, modo eminente de garantizar y proteger aquella primera suprema independencia/libertad del juzgador; al sometimiento de las leyes al oportuno juicio de legitimidad por parte de un órgano judicial, ya se asuma como contraste crítico un texto constitucional o bien determinados principios jurídicos fundamentales basados en el derecho natural o consolidados en la propia tradición jurídica; a la supeditación de la Administración pública tanto a la ley como a los órganos judiciales, sean ordinarios o especiales, pero siempre independientes; a la obligación indeclinable de celebrar elecciones en plazos y tiempos previstos y determinados.

${ }^{41}$ Así lo expresa, por ejemplo, la Constitución Española de 1978 en su Preámbulo: «La Nación española, deseando establecer la justicia, la libertad y la seguridad y promover el bien de cuantos la integran, en uso de su soberanía, proclama su voluntad de: ... Consolidar un Estado de Derecho que asegure el imperio de la ley como expresión de la voluntad popular». 
Es decir, la aportación más característica del Estado de derecho no estriba en la mera urgencia o proclamación de la separación de poderes, sino en su reforzamiento a través de un armónico, efectivo e independiente control de unos por otros. De otro modo, no sería real el imperio del derecho y la igualdad de todos los ciudadanos ante la ley ${ }^{42}$. El sometimiento de los poderes del Estado al derecho exige, pues, el control institucional de unos poderes por otros, manteniendo, precisamente por ello, una real y exquisita independencia los unos de los otros, pues, en la medida en que directa o indirectamente alguno de ellos estuviera, en la medida que fuera, sometido a otro, o bien dependiera políticamente de él, se habrían introducido en la relación jurídica de los mismos elementos extraños al derecho y a la ley.

Ahora bien, tal y como ha quedado expuesta, la descripción que antecede no sería, sin más, fiel reflejo de la naturaleza y organización del Estado en las democracias contemporáneas a causa, sobre todo, y como consecuencia de la multiplicidad y novedad de las relaciones que se han instaurado entre el Estado, como estructura de poder, y la variada complejidad de las sociedades actuales. Complejidad étnica, ideológica, social, cultural y religiosa que, unida al individualismo y soledad a que los modernos sistemas de comunicación y ocio han reducido las relaciones sociales, hace cada vez más difícil articular, expresar y analizar la necesaria racionalidad interna subyacente a todo sistema político. Ejemplo, entre otros, que ofrece una particular utilidad como muestra típica de la mencionada problemática es la complicada convivencia en las democracias contemporáneas, sobre todo ante determinadas cuestiones, entre los presupuestos del Estado de derecho y los contenidos-exigencias del denominado Estado social.

${ }^{42}$ Problema que en sus fundamentos ya había sido planteado en el derecho, la filosofía y la teología desde que San Agustín plantease en La Ciudad de Dios (1. 19, c. 15) que si bien Dios había conferido al hombre la soberanía sobre todos los animales, sin embargo no le había otorgado poder alguno sobre los otros seres humanos. Cada alma es sui iuris: ni puede perder ni renunciar a su libertad originaria. Jamás, pues, podrá ser absoluto el poder de autoridad política alguna. En consecuencia con la doctrina agustiniana, el poder político aparece siempre vinculado a la ley de la justicia, irrevocable e inviolable en cuanto expresión de la voluntad de legislador supremo. Aunque de los principios del derecho romano se podía concluir, como se hizo por algunos en épocas posteriores, que el soberano no estaba vinculado por ley alguna, en el pensamiento medieval el principio del derecho divino de los reyes estuvo siempre sometido a limitaciones fundamentales. En el pensamiento de teólogos y juristas medievales estuvo siempre vigente el brocardo «Rex nihil potest nisi quod iure potest». Hasta el momento no se conoce prueba alguna de que este principio haya sido puesto en duda o seriamente contestado por ningún escritor medieval. Aun aceptando que la autoridad del príncipe deriva directamente de Dios, Sto. Tomás defendía que la obediencia a las autoridades seculares estaba limitada por la ley de la justicia a la que se encontraba sometido el propio monarca (Summa Theologica, I ${ }^{\mathrm{a}}-\mathrm{II}^{\mathrm{a}}{ }^{\mathrm{e}}$, q. 96 , a. 5 y II ${ }^{\text {a }}-I^{\text {ae }}$, q. 42 , a. 2). 


\subsection{El Estado social.}

Cuestión, por otra parte, que de distintas formas y con diferente intensidad ha estado siempre subyacente en el propio funcionamiento y articulación del Estado de derecho, puesto que sólo en los tribunales y en el restringido ámbito de la doctrina adquirían su debido protagonismo los derechos individuales, mientras que en la arena político-legislativa el protagonismo siempre recaía sobre sujetos colectivos en su disputa sobre la consecución de unos determinados fines comunes a través de la distribución de un conjunto de bienes generales.

Así pues, el Estado social es una forma o progresión del Estado de derecho que se caracteriza, en principio, por el hecho de atribuir a los sujetos individuales la titularidad de derechos políticos. Como consecuencia de este reconocimiento generalizado de derechos políticos, se abandona la visión individualista de la sociedad y se urge la tutela de derechos distintos que, normalmente, se caracterizan por la dimensión colectiva de su ejercicio. Circunstancia por la que se les denomina derechos sociales. En este sentido, se debe tener en cuenta que la forma del Estado social no constituye novedad alguna respecto a la categoría Estado de derecho, aunque sí supone perfeccionamiento y profundización de ésta.

Mientras los derechos fundamentales, que de ninguna manera pueden reducirse a los denominados derechos-libertad, en el sentido de libertad negativa o no constreñida, garantizan la tutela de las libertades civiles (libertad personal, política, económica, etc.) y constituyen una efectiva defensa del individuo frente a la intervención del Estado, los derechos sociales representan derechos de participación, de forma especial al poder político y a la distribución de la riqueza social, de modo que la forma de Estado se mueve, a partir de estos presupuestos, entre la garantía de las libertades y la visibilidad de la participación ${ }^{43}$. En el contexto social general, puede decirse que si los derechos fundamentales son garantía del status quo, límite a partir del que se desarrolla y ejercita la libertad, los derechos sociales se encuadran, por el vínculo y necesaria relación que se establecen entre la sociedad y los mecanismos del poder político, en el futuro de las sociedades abiertas y tanto su «formulación» como su satisfacción dependerán del contexto sociocomunitario en que se plantee la efectividad de aquellos.

A partir, pues, de la conceptualización del Estado social, cabe proponer una nueva sistematización básica del Estado de derecho atendiendo a la distinta perspectiva o dimensión desde la que éste se puede analizar. Con la asunción de esta nueva dimensión cabe describir el Estado de derecho como:

43 «España se constituye en un Estado social y democrático de Derecho, que propugna como valores superiores de su ordenamiento jurídico la libertad, la justicia, la igualdad y el pluralismo político» (CE, 1.1). 
a) Estructura formal del sistema jurídico o, lo que es lo mismo, garantía de las libertades fundamentales por medio de la producción de leyes generales y abstractas aplicadas por jueces independientes.

b) Estructura material del sistema jurídico, en cuanto protector y garante de la libertad de concurrencia en cualquier tipo de negocio, concurrencia reconocida y hecha efectiva en el intercambio de sujetos jurídicos, sobre todo en aquellos que por su propia naturaleza tienen una incidencia determinante en el tráfico jurídico-social como, por ejemplo, los de carácter mercantil.

c) Estructura social del sistema jurídico, en cuanto que la cuestión social y las políticas de integración socio-política de las clases trabajadoras y de las propias situaciones y especificidades personales, cada vez más complejas y diversificadas, que suponen un compromiso especial para la sociedad en que el individuo vive, han adquirido especial protagonismo en los regímenes democráticos.

d) Estructura política del sistema jurídico, determinada por la separación y distribución del poder en sujetos diversos y por el protagonismo de la denominada sociedad civil en las estructuras y los órganos de decisión política.

e) Estructura pluralista del sistema jurídico, en cuanto respuesta a las comunidades transnacionales y distintas respecto a sus tradiciones, modos de vida y religión, pero amparadas por un mismo ordenamiento.

Estado social es, pues, en su origen equivalente a Estado participado por la sociedad o, dicho de otro modo, Estado en cuya gestión participa la sociedad mediante cauces jurídicamente determinados y garantizados. Nada tiene que ver con la perversión del mismo operada en alguna «democracias» contemporáneas en las que Estado social ha sido asimilado a Estado paternalista-asistencial. Asimilación en la que se invierte el verdadero sentido y alcance de esta realidad, al convertir en Estado interventor e invasor de la vida personal al Estado que debería de ser controlado por el ciudadano participante en la propia actividad del Estado. En esta dinámica, el ciudadano asume cada vez con mayor descompromiso su instalación en el denominado paradigma de inmunización: los individuos se someten voluntariamente al aparato estatal, creado precisamente para garantizar su propia individualidad, renunciando simultánea y necesariamente a dimensiones propias de su personalidad, víctimas del miedo al compromiso de la decisión exigido por el ejercicio de la libertad y de lo que, según lo dicho, podríamos denominar como sindrome de la vacuna ${ }^{44}$.

${ }^{44}$ La obsesión por las vacunas que, con cierta periodicidad, invade nuestras sociedades en orden a conseguir inmunidad ante la enfermedad, al margen de la posibilidad real del contagio así como de la gravedad de los efectos secundarios de la propia vacuna, constituye ideal pedagógico de la situación socio-política descrita. Cf. ERSPAMER, F., Paura di cambiare. Crisi e critica del concetto di cultura, Donzetti Editore, Roma, 2010, pp. 4-7. 
De este modo, en las sociedades contemporáneas se ha desencadenado un curioso proceso mediante el que la protección brindada por el aparato estatal se ha hecho tan obsesiva que de medio para armonizar la vida en sociedad se ha convertido en el único fin de la vida y exigencia sociales del individuo. El individuo, en nuestras sociedades, tiende de tal modo a salvaguardar su individualidad a través incluso de la conversión en derechos de lo que no llegan a ser sino simples intereses que, paradójicamente, llega a perder su propia individualidad en el magma pseudo-protector del Estado ${ }^{45}$.

${ }^{45}$ Me refiero al proceso mediante el que se ha desplazado el centro/fundamento de los derechos de la persona hacia el individuo: de una concepción personalista de los derechos se ha pasado a una concepción individualista de los mismos. La privacidad personal suplanta a la dignidad de la persona y la no-discriminación del individuo ocupa el lugar de la libertad en una nueva generación de derechos definidos por su carácter absoluto. La concepción antropológica radicalmente individualista, epígono del homo homini lupus y fundamento de la visión libertaria de los derechos, que hoy prevalece en muchos de los planteamientos de tribunales y teóricos del derecho y de la ciencia política, desemboca naturalmente en una hipertrofia de normas y de derechos. De este modo, como mantenía recientemente Marta Cartabia, «chi pensa di vivere in un mondo di lupi, in cui ciascuno è preoccupato solo del proprio interesse individuale, avrà bisogno di molti strumenti di difesa dall'altro, formalizzando ogni aspirazione e ogni bisogno in un diritto garantito dal sistema giuridico: come è stato detto, se viviamo in un mondo di lupi, non ci saranno mai abbastanza regole per ammaestrare i lupi. L'assolutizzazione e la moltiplicazione dei diritti, dunque, non sono soltanto due fenomeni casualmente concomitanti, ma sono entrambi espressione di una medesima concezione dell'uomo e del suo vivere sociale.

«L'aspetto problematico di questa concezione è che questa espansione dell'universodei diritti individuali manca lo scopo che sembra voler perseguire. Se all'origine di tutto il movimento contemporaneo per i diritti umani vi è l'esigenza di costruire un mondo più giusto, o almeno contribuire alla costruzione di un mondo meno ingiusto, il cui centro sia occupato dalla persona umana e dalla sua dignità, occorre chiedersi se l'espansione del numero dei diritti e la rimozione delle loro limitazioni stia servendo questo obiettivo. Qui sorge il sospetto che i diritti illimitati nel contenuto e nel numero siano esposti a una degenerazione utopistica» (M. Cartabia, «Tempo da lupi per i diritti in Europa», L'Osservatore Romano, 10-10-2010, p.4). Dinámica que está haciendo verdad, por una parte, la sentencia de Voltaire «un droit porté trop loin devient une injustice», invirtiendo, de este modo, el sentido profundo y función de los derechos humanos que, de defensa de la persona contra la degeneración y abuso del poder, se han transformado en instrumentos privilegiados de poder; $y$, por otra, la promoción por parte de los poderes públicos, en nombre de los derechos humanos, de lo que no pasan de ser simples intereses de determinadas personas, colectivos o grupos de presión. Hipertrofia del uso o invocación abusivos del o de los derechos que afecta muy directamente a todas las vertientes del ordenamiento jurídico, como se deduce del siguiente comentario: «Cette maxime, attribuée à Voltaire, illustre en quelques mots une théorie séculaire, dont la destinée est à la fois surprenante et remarquable. Malgré le grand intérêt que représente l'étude du développement historique, doctrinal et jurisprudentiel de cette notion, nous nous contenterons ici de préciser d'une manière laconique que les auteurs s'entendent pour définir l'abus de droit comme «la faute dans l'usage ou l'exercice des droits». La théorie de l'abus de droit conduit à 
Es, pues, evidente que la realidad actualmente subyacente al topos Estado de derecho es mucho más compleja y sutil que la del Estado que surge de la modernidad, donde los límites y contenidos eran mucho más claros y comunes, al integrarlo todo bajo la categoría de Estado-Nación, en la que quedaban incluidos bajo el mismo signo y razón de identidad nacional lengua, religión, costumbres, tradición y ritos sociales. Hoy, sin embargo, aun admitiendo el principio nacional como constitutivo geográfico-político fundamental del Estado, se ha de asumir que dentro de las fronteras territoriales y jurídicas de las democracias occidentales habitan religiones, nacionalidades, civilizaciones y razas diversas. Situación que exige en el Estado de derecho la neutralidad ética del derecho y la política. Entendida o aplicada esta neutralidad no sólo en lo que se refiere al procedimiento democrático de producción jurídica, sino a la sustracción del debate político de todos aquellos asuntos de carácter ético que aun con incidencia socio-política no son susceptibles de una regulación jurídica imparcial: como acontece, por ejemplo, con los contenidos de ciertos modelos educativos. Circunstancia que nos lleva por el camino de la segunda parte del título de esta reflexión y nos aboca a preguntarnos por el pluralismo y dentro del género, más en concreto, por la relación/ proporcionalidad del Estado - pluralismo religioso.

\section{EL PLURALISMO RELIGIOSO COMO IDENTIDAD DEMOCRÁTICA DEL ESTADO.}

Se entiende, al menos en el habla común del español, tal como lo recoge el Diccionario de la Real Academia de la Lengua, por pluralismo el «sistema por el que se acepta o reconoce la pluralidad de doctrinas o métodos en materia política, económica, etc.».

\subsection{Sentido del término pluralismo.}

Ahora bien, si reconducimos esta definición a su uso en el ámbito jurídico-constitucional nos encontramos, en principio, con un doble significado del mismo, según hagamos referencia al pluralismo ideológico o bien al pluralismo institucional.

En el primer caso, pluralismo se opone a totalitarismo o a integrismo, al margen del calificativo u orientación que se les atribuya, e indica la afirmación de la oportunidad e incluso de la obligatoriedad de que las autoridades consientan o favorezcan la expresión o divulgación de una variedad (pluralidad) de opiniones, creencias y de concepciones del mundo, diversas entre sí e incluso de aquella o aquellas que sean profesadas por la mayoría de los ciudadanos, incluidas las propias autoridades. Obli-

envisager l'exercice des droits à travers le prisme de principes jugés supérieurs, telle l'équité» (MARTIN, S., «Pour une réception de la théorie de l'imprévision en droit positif québécois», Les Cahiers de droit, 34, n² 2, 1993, p. 613). 
gación o deber que, al menos en el caso español, les vienen impuestos a los poderes públicos por el propio ordenamiento ${ }^{46}$. Pluralismo ideológico que ampara o da cobertura a la libertad religiosa, la libertad ideológica, libertad de expresión, etc.

Por pluralismo se entiende, en el segundo sentido, la afirmación de la necesidad y la obligación de que los poderes públicos no se concentren en un único órgano sino que, por el contrario, aparezcan constitucionalmente distribuidos entre una organización principal (Estado) y otras, de carácter social o político, coordinadas con aquella, según la naturaleza y fines de ambas. A su vez, el Estado debe ser plural no sólo en cuanto a su estructura orgánica sino también en lo que afecta a la conformación interna de los distintos órganos que lo constituyen. Propiedad atribuible también a instituciones $\mathrm{u}$ organizaciones sociales o políticas correspondientes a las distintas comunidades de las que simultáneamente pueden formar parte los individuos dentro de la sociedad, debido a las diferentes afiliaciones y a los variados lazos que naturalmente se establecen entre los hombres, según sus circunstancias geográficas, históricas o culturales. Pluralismo institucional que legitimaría, por ejemplo, la existencia y exigencia de los denominados derechos de desarrollo social, tales como la familia, las confesiones religiosas, las comunidades escolares, etc.

Desde su dimensión operativa o de práctica del pluralismo, nos atrevemos a definirlo como el conjunto de circunstancias sociales, disposiciones políticas y actitudes personales que conforman y delimitan ámbitos de convivencia en que el poder, sea político, económico, intelectual, educativo, ideológico, etc. está justa y equitativamente distribuido, compartido y reconocido. Nos hallaríamos ante lo que puede denominarse, en perífrasis más profunda y comprometida que lo que pudiera parecer a primera vista, democracia como forma de vida. Se ha de tener siempre muy presente que sólo en una sociedad basada en el pluralismo pueden fundarse legítimamente los límites al ejercicio de los derechos fundamentales de la persona, así como la restricción ordenada de los denominados derechos sociales.

Cualquiera, pues, sea la conceptualización del pluralismo que asumamos, es claro que la libertad religiosa, tanto en su radicación personal como desde su proyección social es elemento determinante y contrastante de la autenticidad del Estado social y de derecho, en la medida en que el pluralismo es asumido como uno de los valores superiores del ordenamiento por parte de los regímenes políticos que se constituyen sobre principios democráticos y se conforman en el ámbito de sociedades abiertas.

46 «Corresponde a los poderes públicos promover las condiciones para que la libertad y la igualdad del individuo y de los grupos en que se integra sean reales y efectivas; remover los obstáculos que impidan o dificulten su plenitud y facilitar la participación de todos los ciudadanos en la vida política, económica, cultural y social» (CE, 9.2). 
A pesar de la dificultad que en si mismo entraña el intento de definir o delimitar en y desde todas sus perspectivas e implicaciones el pluralismo, y manteniéndonos siempre en la perspectiva prevalentemente operativa del término, según acabamos de apuntar, nos interesa señalar de entre toda la compleja red de relaciones en que se articula este concepto, sobre todo en cuanto perspectiva metodológica, el hecho de que los requisitos, condiciones y presupuestos que posibilitan el ejercicio del pluralismo se profundizan, maduran y enriquecen con su ejercicio y puesta en práctica. En este sentido, pluralismo y requisitos de ejercicio se integran en una dialéctica positiva de crecimiento en espiral: a mayor pluralismo, mejores condiciones y posibilidades de un ejercicio que, a su vez, magnifica y facilita los requisitos que acaban haciendo progresivamente más necesaria la existencia del pluralismo.

Entendido así, el pluralismo enraíza y se consolida en una concepción del hombre basada, desde el convencimiento jurídico-formal y el reconocimiento práctico-material, en la dignidad humana, así como en los atributos, características y exigencias en ella implicados junto con los derechos personales y sociales que de ella derivan. Por tanto, sólo es posible en condiciones, formales y materiales, de igualdad y libertad, única posibilidad de realización material y formal de la justicia ${ }^{47}$, pues sólo cuando se consiga una aceptación tal de la igualdad que nunca la libertad de una persona pueda ser invocada como límite cercenador de la de otras se habrá consolidado la auténtica justicia, irrefutable testigo del verdadero pluralismo ${ }^{48}$. No cabe, pues, la menor duda respecto a que preguntarse por la naturaleza, el significado o los contenidos del pluralismo equivale a acercarse a una cuestión que afecta a todas las dimensiones del hombre y de la sociedad.

\subsection{El pluralismo político, principio y valor del ordenamiento.}

Consciente de la variedad de ámbitos y ciencias, desde las positivas hasta la teología, que invocan el pluralismo como referencia crítica de sus contenidos e incluso de sus métodos de trabajo, interesa en esta sede trazar siquiera un breve apunte sobre la dimensión política del principio pluralista, que

${ }^{47}$ Realización plena de la justicia que sólo se alcanza cuando igualdad y libertad se articulan y armonizan en y desde la perspectiva de la fraternidad, lugar de donde procede y brota la auténtica solidaridad: perspectiva cuyo desarrollo excede los límites de este análisis.

48 «En una sociedad pluralista, la libertad personal de los individuos que la componen jamás podrá ser invocada como límite de la libertad de los demás... Así pues, el derecho o el ejercicio de la libertad del otro nunca puede ser límite del ejercicio del propio derecho o libertad; antes al contrario, es condición sine qua non que necesariamente debe existir para posibilitar su propia existencia y efectividad práctica, pues, en la medida en que mi derecho roce o lesione el ajeno, se estará negando a si mismo» (CAlvo Espiga, A., «Paradojas del pluralismo», Estudios de Deusto 51/2, 2003, pp. 95-96). 
comúnmente se ha dado en denominar pluralismo político ${ }^{49}$. En la ciencia política y en la sociología, se ha entendido por pluralismo bien la doctrina política opuesta a la teoría monista del Estado ${ }^{50}$, o bien una hermenéutica de análisis y comprensión de las sociedades e instituciones humanas distintas del Estado. El pluralismo contemporáneo, sobre todo tal y como se ha desarrollado en Inglaterra y América entre los años 1900 y 1930, surgió como consecuencia de la imposibilidad estructural que atenazó al Estado moderno a la hora de dar respuesta a importantes problemas surgidos de modos de organización social, hasta entonces, desconocidos, así como de las nuevas formas de articulación de los propios Estados. Las transformaciones surgidas en la sociedad civil como consecuencia del aumento de la movilidad de las personas sobre todo debido a la mejora, respecto a siglos anteriores, de los medios de locomoción; el abandono por parte de sus habitantes de zonas pobres en búsqueda de mejoras personales, sociales y económicas; la «conciencia de clase» que surge en las clases trabajadoras junto con la percepción, unas veces, y convencimiento, otras, de que la sociedad es un entramado mucho más complejo que el Estado titular del poder de ordenarla, originó, entre otras causas, una importante crisis en el Estado moderno que, para responder a los retos procedentes de esta nueva sociedad y garantizar su propia subsistencia orgánica, no encontró otra salida que la de asumir como valor y principio de su propia estructura jurídico-institucional el pluralismo y articular, en su consecuencia, su propia organización según este mismo principio.

Es, sobre todo, a partir de los años 1945-1950 cuando se generaliza la utilización de un nuevo calificativo para designar al Estado democrático, el de pluralista. En cierto modo, podría decirse, y no sólo ni principalmente por razones cronológicas, que el Estado pluralista no es sino fruto de la coexistencia e influencia conceptual que los contenidos del Estado social han tenido en determinados aspectos del Estado de derecho. Se viene a conside-

49 Por lo que respecta al pluralismo en cuanto metodología jurídica y como criterio de comprensión del derecho y explicitación de la ciencia jurídica, puede verse MORETBaIlly, J., «Ambitions et ambiüités des pluralismes juridiques», Droits 35/2, 2002, pp. 105-206.

${ }^{50}$ Desde esta perspectiva socio-política entendemos por Estado monista aquel en que toda su estructura se basa en la existencia de una verdad oficial única, respecto a la que no se admite disentimiento público alguno, donde no cabe la diversidad ideológica de grupos o asociaciones y, mucho menos, libertad para crearlos. Normalmente son Estados de partido único, así como de sindicatos y corporaciones profesionales únicas, en las situaciones en que se permitan, pues, normalmente, Estado, Gobierno y partido se autodiluyen en un conglomerado de poder que lo abarca todo. Respecto a su relación con el fenómeno religioso, para esta clase de Estado, sólo existen dos alternativas: o prohibición de cualquier organización religiosa, por contrarias e incompatibles con la ideología oficial, o permisión de una única confesión religiosa a la que se suele dotar de carácter oficial o estatal. 
rar, pues, Estado pluralista aquel en que el ordenamiento estatal reconoce y garantiza la existencia de una multiplicidad de centros y grupos de poder: sociales, religiosos, étnicos, políticos, institucionales y económicos. Se trata, en realidad, de un Estado en que no existe una única fuente de autoridad, ni un sistema unitario de derecho, ni un órgano central de administración, ni una voluntad política general.

Si bien, para algunos, el considerado modelo pluralista conlleva la construcción de una democracia dinámica y la participación del mayor número de sujetos en los procesos de decisión, sin embargo comporta el riesgo de duplicación o multiplicación de funciones y competencias, de conflictos entre los diversos centros de poder e interés, de fragmentación y disgregación de la sociedad, con el riesgo de atomizarse en pequeñas sociedades cerradas, amén de la pérdida del concepto clásico de soberanía estatal así como de las progresivas limitaciones del ejercicio de los derechos de libertad, consecuencia, en buena medida, de la complejidad con que se articulan las relaciones en los nuevos Estados plural-transnaciona$1 \mathrm{~s}^{51}$. Llevado, pues, el pluralismo a esos niveles, el Estado resultante más que de plural o pluralista habría de ser calificado de multiétnico, multi-religioso, multi-partitocrático, multi-social, etc., con la consiguiente quiebra de principios fundamentales del Estado de derecho tales como la igualdad, la libertad, la justicia, la participación en la gestión y control de lo público. Quiebra que conduce al dominio y prevalencia del Estado-aparato sobre el Estado social, con la consiguiente y necesaria disminución y fuerte control por parte del poder político del ejercicio de los derechos fundamentales de la persona. La atomización de la sociedad como consecuencia de la multiplicidad derivada de características o circunstancias secundarias de la persona a través de multi-Estados genera, a fin de cuentas, unas sociedades cerradas, fuertemente estratificadas y, finalmente, discriminadoras en las que los derechos acaban dependiendo no del ser personal sino del accidente del lugar de nacimiento o residencia, del color de la piel, de la pertenencia familiar o del uso de tal o cual idioma.

La teoría del Estado soberano, elaborada principalmente por juristas y que como hemos señalado al principio corresponde al denominado Estado moderno, provocaba graves dificultades desde el punto de vista político, sobre todo, en la medida en que soberanía se confundía con omnipotencia, en tantos casos absolutista, del Estado. El desacreditado Estado soberano fue el principal objetivo crítico de las teorías y doctrinas pluralistas que, desplazando su interés y punto de mira del Estado a la sociedad y grupos sociales, reivindicaron derechos y protagonismo social para colectivos profesionales

${ }^{51}$ Cf. Cerrina Feroni, G., «Le forme di Stato», en Carrozza, P., Di Giovine A. y Ferrari, G. F., Diritto costituzionale comparato, Editori Laterza, Roma-Bari, 2010², pp. 697-703. 
y asociaciones, en oposición y como reivindicación del protagonismo de la sociedad frente al Estado.

Tampoco ha sido ajeno a esta consolidación de la práctica democrática el progresivo reconocimiento de los derechos del hombre que, en cierto modo, ha despolitizado, en su sentido más estricto, el concepto de democracia para convertirlo en telón de fondo o marco en que delinear o tipificar las relaciones humanas, asumiendo como fundamento basilar de las mismas el respeto a la igual dignidad de todos los hombres y a sus ideas, aun cuando no se compartan: éste precisamente sería el punto de inflexión en que se entrecruzan tolerancia y pluralismo. Bien entendido que este proceso se ha percibido y vivido con distinta intensidad y profundidad según la sensibilidad democrática de las correspondientes comunidades políticas. Cuanto más abiertas son las sociedades con más fuerza se ha experimentado la despolitización de la democracia, puesto que ésta ha pasado de ser considerada como un valor o actitud política a ser vivida como un valor-principio social. Por el contrario, en aquellas sociedades cerradas que se han configurado como formalmente democráticas sin que ello haya calado en los hábitos sociales de ciudadanos y dirigentes, la democracia ha experimentado el proceso inverso de una politización cada vez más fuerte, llegando la dimensión política de la sociedad a fagocitar y exclusivizar la democracia que, de este modo, acaba convirtiéndose en mera coartada legitimadora de la fuerza e incluso impunidad partidistas. Sociedades que, como hemos señalado anteriormente, aunque amparadas en la nota pluralista, responden realmente a colectivos cerrados en sus peculiares particularismos impermeables, además, a toda intercomunicación e inter-socialización con aquellos grupos de características étnicas, lingüísticas o religiosas distintas.

Finalmente, debemos notar como el ideal democrático, que en un primer momento aparece como conquista de la libertad política, evoluciona, en razón de una necesaria dinámica interna, hacia la defensa y promoción de cualquier libertad, sobre todo de la de pensamiento; por lo que, con toda lógica, junto al ideal democrático necesariamente debía afirmarse la legitimidad, incluso la necesidad, del pluralismo. Precisamente de esa dimensión pluralista extrae su razón de ser el ideal democrático en cuanto proceso concurrente y competitivo para hacer llegar al poder una verdad o una ideología: la misma fuerza que legitima y garantiza la lucha entre las ideas no sólo ha de impedir cualquier ataque contra las personas, sino garantizar el inalienable derecho del ser humano a tener, defender y exponer sus propias ideas en el marco de la libre concurrencia de pareceres y convicciones.

\subsection{Pluralismo y ejercicio de las creencias religiosas: paradoja y com- promiso.}

Pero, en el título que encabeza esta exposición se habla de pluralismo religioso. Al plantear la relación entre Estado de derecho y pluralismo religioso, estamos asumiendo inicialmente el significado de este segundo elemento 
del enunciado en un sentido sociológico fruto o consecuencia de la confluencia del pluralismo ideológico y del pluralismo institucional. Me refiero al hecho de la presencia en la sociedad de distintas Iglesias o Confesiones religiosas, como expresión del ejercicio del derecho de libertad religiosa de las personas que la integran y que simultáneamente son ciudadanos miembros, desde una perspectiva jurídico-política, del Estado. De nuevo nos hallamos ante una dinámica de encuentro entre el hecho social del pluralismo religioso y la exigencia jurídica del pluralismo del y en el Estado respecto al hecho religioso en cuanto concreción del ejercicio individual y colectivo de un derecho fundamental.

Ahora bien, al referirme en esta sede al pluralismo religioso no lo planteo como una cuestión meramente sociológica o de hecho constatable a través de la plural y variada convivencia o coexistencia de distintas confesiones religiosas en un mismo lugar o territorio, sino que nuestro intento se dirige a reflexionar sobre este fenómeno desde la perspectiva del Estado pluralista. Es decir, la cuestión que, sobre todo, interesa poner de relieve es como el pluralismo religioso existente en una sociedad determinada no es un hecho o circunstancia ajenos al Estado de derecho, sino que, por el contrario, su respeto, garantía y protección son exigencia que brota de la misma esencia y presupuestos del Estado de derecho. O, dicho en forma negativa, la falta de respeto y protección por el Estado del pluralismo religioso constituye indicio indiscutible de que el mismo carecería de una de las notas o propiedades que lo caracterizan como verdadero Estado de derecho.

Sólo en las sociedades abiertas, tal y como han sido teorizadas a partir del occidental dualismo cristiano, a excepción quizás del caso japonés único país en que se ha consolidado un sistema de gobierno democrático de corte occidental impuesto por la fuerza, puede hablarse de pluralismo religioso, porque no en vano sociedad abierta se corresponde necesariamente con sociedad plural. Ello significa, por tanto, que el pluralismo ha de concebirse primaria y necesariamente como un valor personal y social, no como una ideología al servicio de determinados intereses. Pluralismo que engloba, en cuanto que la supera positivamente, a la tolerancia y, en consecuencia, no cabe hablar de pluralismo donde exista el mínimo rastro de dogmatismo ideológico, arracionalidad fideista o fanatismo religioso, tanto en su proyección positiva como en la que fanáticamente niega toda posibilidad a la dimensión religiosa de la persona. El pluralismo, en las sociedades abiertas y democráticas, requiere que las Confesiones religiosas gocen de libertad en el ejercicio público de sus manifestaciones, así como que estén institucional y estructuralmente separadas del Estado pero, sobre todo, requiere que la sociedad civil sea verdaderamente autónoma respecto al Estado. Sólo a partir de esta autonomía, la sociedad civil será verdaderamente independiente del Estado y éste actuará siempre al servicio de aquella, con lo que el propio Estado asumirá el respeto y protección del pluralismo religioso como uno de los servicios esenciales que debe prestar a la sociedad. 
Tanto el Estado que se convierte en brazo secular de una Iglesia o Confesión concretas como el Estado que politiza o ideologiza en una determinada dirección a la sociedad suponen idéntica amenaza para el pluralismo. Sin embargo, antes de seguir adelante, hemos de insistir en que lo expuesto hasta el momento responde a una cosmovisión dualista-cristiana tal y como se ha consolidado en Occidente: el Islam, por ejemplo, la rechaza categóricamente, a pesar de algunas débiles excepciones ${ }^{52}$; y lo mismo, aunque quizás no con tanta nitidez y resonancia social, acontece en determinadas regiones musulmanas de África y Asia, como se advierte en las recientes matanzas y persecuciones de cristianos en distintos lugares de estos continentes ${ }^{53}$. De nuevo rebrota aquí bajo el signo, en este caso, de la comprensión efectiva del derecho de libertad religiosa el importante problema presente, como ya hemos señalado, en el debate contemporáneo sobre el derecho y los derechos de la persona y que tiene una gran incidencia en el asunto que aquí nos ocupa: me refiero a la cuestión de la universalidad de los derechos humanos, que no se ha de confundir con su absolutización individualista ${ }^{54}$.

52 Cf. Campanini, M., Il pensiero islamico contemporaneo, Il Mulino, Bolonia, 2005, pp. 35-72; Colombo, V., Islam. Istruzioni per l'uso, Arnoldo Mondadori, s/1, 2009, passim; EADEM, Vietato in nome di Allah. Libri e intellettuali messi al bando nel mondo islamico, Lindau, Turín, 2010, passim.

${ }^{53}$ A la grave situación de persecución hasta el martirio a que se hallan sometidos los cristianos, y de forma especial los católicos, en distintas regiones de África y Asia, recuérdense las matanzas de cristianos acaecidas la pasada Navidad 2010-2011 en distintas naciones de estos continentes, se ha añadir la cristianofobia que progresivamente adquiere más fuerte virulencia en las «democracias» europeas, tanto por lo que respecta a las cada vez mayores dificultades con que los cristianos se encuentran a la hora de profesar públicamente su fe como al desinterés que Estados e instituciones nacionales y supranacionales europeas muestran ante las persecuciones sufridas por los cristianos. Quienes en nombre de las libertades y derechos humanos denuncian y condenan actitudes o comportamientos de poderes públicos lesivos para ciertos «derechos» (¿?) de los individuos permanecen silenciosos e indolentes ante verdaderas masacres de cristianos. Los mismos que hipócritamente se rasgan sus carísimas vestiduras ante, por ejemplo, el Reglamento de un centro docente que no permite a sus alumnos la presencia en el aula con la cabeza cubierta, cuando esta norma afecta a alumnas que conociendo previamente estas disposiciones y habiéndolas observado habitualmente, deciden un buen día cubrirse por motivos religiosos, han guardado sorprendente silencio ante condenas a muerte de mujeres por el simple hecho de ser cristianas y callan ante las decenas de cristianos martirizados cada año a causa de su fe.

${ }^{54}$ A medida, como hemos notado anteriormente, que determinados intereses individuales sostenidos y promocionados por ciertos grupos se cuelan en nuestro ordenamientos, a través de cierta jurisprudencia, nunca mejor que ahora calificada de jurisprudencia de intereses aunque la suscriban tribunales de vitola internacional, con el marchamo de derechos, se menguan hasta la asfixia los espacios propios para el ejercicio del derecho de libertad religiosa, hasta la consumación de una, a veces, cruel paradoja antidemo- 
Abordaré la última parte de esta exposición desde la paradoja que representa para el Estado de derecho el pluralismo religioso y que tiene que ver, por una parte, con la dimensión esencialmente personal y de conciencia del derecho de libertad religiosa; y, por otra, con la manifestación social y pública de este derecho que, con frecuencia, plantea al Estado la necesidad de establecer determinadas relaciones institucionalizadas con distintos grupos confesionales o religiosos.

Aun cuando sea cierto que en casos extremos y en determinados momentos o circunstancias, por desgracia cada vez más frecuentes, sólo puedan ser invocados como horizonte de denuncia, cabe recordar que constituye un tópico comúnmente aceptado que la persona y sus derechos se han convertido en contraste básico y recurrente de autenticidad para el Estado de derecho. Más, todo ordenamiento que aspire a una legitimidad social y jurídica plena en el escenario de la sociedad internacional deberá garantizar espacios jurídicos suficientes para que sus ciudadanos ejerzan el derecho fundamental más íntimo de la persona, y por ello más lábil: la libertad religiosa. Libertad ideológica, libertad religiosa y libertad de conciencia conforman en los Estados de derecho una trilogía de garantía jurídica presente en toda referencia a los derechos humanos, cualquiera que sea el ámbito jurídico desde el que se realice. Los ordenamientos estatales se encuentran, pues, ante la novedad y necesidad de crear espacios normativos en que se regule y proteja el ejercicio de las libertades referidas, en cuanto que constituyen o determinan uno de los más importantes derechos fundamentales de los ciudadanos. En efecto, se trata, sin duda alguna, del que más profundamente compromete a la persona y, por contraste, el que con menos medios de protección y defensa cuenta tanto desde su propia conformación jurídica y concreción personal como desde los contenidos dogmáticos o desde los idearios de las distintas confesiones religiosas ${ }^{55}$.

Precisamente debido a la desnuda fragilidad socio-jurídica del derecho de libertad religiosa, la creación de entornos jurídicos que faciliten y ayuden, cada vez más y mejor, el desarrollo de la persona y de sus potencialidades, a través de la garantía legal del pluralismo, la libertad ideológica, religiosa, etc., constituye actualmente una de las piezas-clave de asentamiento y garantía de todo sistema democrático. Es indudable que tanto mayor y mejor será el margen de ejercicio de la libertad cuanto mayor y mejor armonía entre orden social y conciencia/libertad personal

crática, pues sólo acaba respetándose con la contundencia que acompaña al miedo en los cobardes el ejercicio sin restricciones de aquellas religiones dispuestas a utilizar la violencia para imponer su credo o para hacer desaparecer los ajenos.

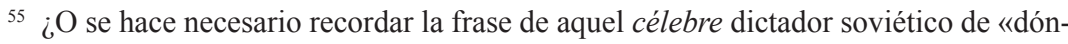
de están los cañones de la Iglesia»? ¿o la de aquel otro demócrata español que definía a la Iglesia Católica como tigre de papel? 
consiga la legislación en todos aquellos asuntos en que norma estatal y conciencia se entrecruzan ${ }^{56}$.

Así pues, el reconocimiento de las libertades más íntimas de la persona exige del Estado de derecho la progresiva integración de la norma jurídica en la esfera de la actividad social directamente relacionada con y derivada de la íntima conciencia del ser humano, instancia última de su ser personal, que incluye de forma eminente su dimensión religiosa. Deber y responsabilidad que derivan no sólo de la aceptación del valor derechos humanos como principio informador del propio Estado y de su ordenamiento, sino también del hecho de que el Estado de derecho ha de estar siempre al servicio de la persona y supeditado a la protección, promoción y salvaguarda de la sociedad que institucionalmente le precede y supera.

En cuanto democrático e inserto en una sociedad plural, abierta, adulta y libre, donde prima el criterio de la justa igualdad de todos ante la ley, el Estado de derecho, además, no debe ir más allá de ser árbitro y garante, nunca orientador ideológico, de libertad y pluralismo. La exquisita neutralidad que se exige a todo árbitro y moderador es la que debe observar, en todos los órdenes, el Estado en las sociedades abiertas y democráticas que, simultáneamente, determinan y conforman al Estado de derecho. Árbitro y moderador, ni contendiente ideológico, ni orientador, ni promotor o controlador determinante de criterios o valores sociales ${ }^{57}$.

${ }^{56}$ Cf. Calvo Espiga, A., «La libertad religiosa en las sociedades democráticas», $L u$ men 57, 2008, pp. 281-312.

${ }^{57} \mathrm{Si}$ todavía no hace muchos años se habló, desde distintas perspectivas, de la superación de las ideologías, nos encontramos en la actualidad con un peligroso renacer del ideologismo político y social. Me refiero a la excesiva polarización, avalada y promocionada por y desde los poderes políticos, cuando se absolutizan ciertas regiones o aspectos limitados de nuestro mundo experimental. Rahner denominaba a esta clase de absolutización ideología de la inmanencia. En sentido contrario, nos encontraríamos con la ideología de la transmanencia que exalta lo por ella concebido como definitivo o infinito hasta tal extremo que aquello que no entra en ese grado de superioridad queda totalmente anulado, personas incluidas, aun en lo que pudieran poseer de valor relativo. Por último, en la ideología de la trascendencia, profundamente relativista, no se valora positivamente ni lo inmanente ni lo trascendente, sino que constituye una especie de comprometida y buscada evasión ante todo lo que pudiera significar o implicar cualquier compromiso de signo claramente definido. Las ideologías dominantes hoy en la sociedad asumen el denominador común de la confusión ideológica propiciada por la tensión derivada del rechazo, por alienante, de la admisión de valores absolutos frente a la así denominada autenticidad del simple vivir de impresiones y apetencias sin referencia a orden o jerarquía alguna. Confusión que favorece y hasta legitima el protagonismo de unas estructuras políticas cada vez más lejanas de la persona y, en consecuencia, más condicionantes, conttroladoras y, en definitiva, manipuladoras de su vida y derechos. Cf., al respecto, Coste, R., «Marxisme et Théologie», Nouvelle Revue Théologique 106, 1974, pp. 918-933; Ellul, J., L'spérance oublié, Gallimard, Paris, 1973, pp. 57-58; GIL ORTEGA, U., «Superación de las ideologías», Lumen 32, 1983, pp. 53-56; LaUth, R., «Ideología 
Neutralidad, protección, fomento y respeto del pluralismo son, en reiterada doctrina del Tribunal Supremo Español, principios que no sólo no deben ser sobrepasados en ningún momento y circunstancia por los poderes públicos, sino que han de ser asumidos como lo que realmente son y significan, principios informadores y determinantes de la actuación del Estado:

«Ello es consecuencia del pluralismo, consagrado como valor superior de nuestro ordenamiento jurídico, y del deber de neutralidad ideológica del Estado, que prohíbe a éste incurrir en cualquier forma de proselitismo... En una sociedad democrática, no debe ser la Administración... quien se erija en árbitro de las cuestiones morales controvertidas. Estas pertenecen al ámbito del libre debate en la sociedad civil... y por supuesto al de las conciencias individuales... $\rangle^{58}$.

\section{A MODO DE COLOFÓN CONCLUSIVO.}

Al final de esta exposición cabe, en primer lugar, insistir en que la presencia social de las opciones religiosas no debe ser ignorada por el ordenamiento del Estado o considerada como un asunto menor o intrascendente desde su dimensión jurídica. Antes al contrario, en el ámbito de la ciencia sociológica, jurídica y política se ha de suscitar y mantener una reflexión seria y contrastada tanto sobre el fenómeno religioso como sobre el hecho de la pertenencia religiosa personal, con las exigencias sociales de ella derivadas, puesto que, en nuestras sociedades contemporáneas, todo lo relacionado con la religión y su vivencia personal constituye un excelente punto de contraste para comprobar cómo y hasta qué punto la racionalidad o razonabilidad condicionan y determinan, por una parte, la virtualidad personalizadota de la pertenencia social y, por otra, la autenticidad del Estado de derecho.

Las relaciones sociales que el derecho y, consecuentemente, los aparatos estatales, tanto en su dimensión jurídica como política, mantienen y han mantenido con las Confesiones religiosas sirven perfectamente de indicio pedagógico para delimitar con mayor precisión y urgir que cualquier pertenencia personal, sea religiosa, social o ideológica, ha de ser racional y crítica frente a la cada vez más acusada tendencia, sobre todo en las adscripciones políticas, hacia el predominio de lo socio-afectivo e irracional. La misma crítica racionalidad exigible al Estado de derecho en su actitud de neutralidad ante lo religioso, al margen y por encima de cualquier tentación intervencionista, así como en su deber de promoción y protección del ejercicio del derecho de libertad religiosa como uno de los más básicos y fundamentales de los que son titulares sus ciudadanos (CE, art. 9, 2).

y Ciencia», Atlántida 3, 1965, pp. 371-372; RAHnER, K., «Ideología y Cristianismo», Concilium 6, 1965, pp. 42-62.

58 STS de 11 de febrero de 2009, FJ 10. 
Y ante la plural variedad de credos con los que se encuentra actualmente el Estado democrático, quizás sea útil acudir a la historia del Cristianismo como pedagogía social y jurídica de la actitud que las autoridades estatales debieran asumir ante el fenómeno religioso. La sociedad en que nació y se difundió el Cristianismo, tanto en su vertiente oriental como occidental, estaba regida y ordenada por un sistema jurídico muy elaborado y totalmente marginal a la nueva fe, el derecho romano. Los predicadores del Evangelio jamás presentaron su fe como un conjunto de normas, reglas o prescripciones con la pretensión de 'sustituir a' o 'anular' ningún sistema jurídico o cuerpo legal vigente en la sociedad de su tiempo. Situación que claramente contrasta con la doctrina mosáica o con la predicación de Mahoma, dirigidas a grupos humanos socialmente invertebrados donde el derecho como fenómeno social articulado era prácticamente inexistente. Por ello, el Pentatéuco y el Corán no son considerados únicamente como libros religiosos, sino también como recopilaciones o colecciones de reglas de derecho y de normas puramente temporales, aunque de exclusivo origen divino, y reguladoras de aspectos estrictamente socio-temporales y políticos de la actividad personal. La pertenencia evangélica al orientarse primaria y directamente a una dimensión personal y comunitaria distinta, por principio, de aquella en que se desenvuelven las instituciones exclusiva e inmediatamente jurídicas, posibilita, facilita y urge la observación 'racional', sin atisbo de imposición 'extra' o 'metaracional' alguna, de sus distintas pertenencias, incluida la religiosa, pues la auténtica conversión al Evangelio se fundamenta y es necesariamente consecuencia de la libertad humana, es decir, de la más razonada actividad de la persona. Por su propia esencia, el cristianismo exige y se funda en pertenencias críticas, conscientes, racionales, personalizadas, como único medio efectivamente válido de situar a la persona y su dignidad por encima de cualquier pertenencia social derivada y secundaria, en razón de su radical trascendencia, que para la fe cristiana procede de la inhabitación personal del Espíritu Santo ${ }^{59}$.

Y difícilmente, por lo que respecta al pluralismo religioso, podría sintetizarse mejor la actitud que los Estados democráticos han de observar ante el derecho de libertad religiosa y su ejercicio que como reiteradamente lo ha propuesto el Tribunal Europeo de Derechos Humanos, quien no sólo considera la libertad religiosa como «uno de los cimientos de la sociedad democrática», sino que reitera de forma indubitada que «la libertad religiosa, siendo elemento esencial de la identidad de los creyentes y de su concepción de la vida, es también, y sobre todo, un bien preciado para ateos, agnósticos,

${ }^{59}$ Cf. Malaurie, Ph., «Le droit et l'exigence de dignité», Études, n. 398/5, 2003, pp. 622-627. 
escépticos e indiferentes, consecuencia necesaria del pluralismo consustancial con una sociedad democrática» ${ }^{60}$.

En consonancia, pues, con la propia naturaleza del Estado respetuoso de los derechos humanos, éste, aún cuando se presente como idealmente laico y neutralmente agnóstico, no debe presentarse ni ser considerado como una especie de enemigo público imbuido del prejuicio de exclusión de lo sacro de su horizonte de actuación; pues, de comportarse así, el Estado de derecho habría abdicado de uno de sus más netos e inmediatos orígenes políticos y jurídicos, el de la equidistancia ideológica, moral y religiosa del Estado neutral ante la autonomía de la sociedad y de sus ciudadanos, evitando la tentación totalitaria de transformar la ideología en moral pública. La aceptación social de la pluralidad religiosa por parte del Estado, su consiguiente neutralidad o su laicidad abierta respecto a las Confesiones religiosas, así como el respeto a sus doctrinas y estructura interna constituyen una exigencia jurídica, y no una mera conveniencia estratégica, de la propia naturaleza y función del Estado democrático que se configura como social, plural y de derecho, en el que los derechos humanos y la centralidad de la persona constituyen el marco y razón de ser del propio Estado. La garantía y protección del pluralismo religioso se erige, sin duda alguna, en inequívoca seña de identidad del Estado de derecho.

\section{TITLE: Rule of law and religious pluralism.}

RESUMEN: El fenómeno de la secularización coincide en nuestras sociedades occidentales con una presencia pública cada vez más fuerte del fenómeno religioso. La dimensión social del ejercicio del derecho de libertad religiosa en sociedades cada vez más plurales constituye un verdadero test de autenticidad para las democracias contemporáneas y para sus ordenamientos jurídicos. La protección y promoción del pluralismo religioso por parte de los poderes públicos es uno de los principales retos a que han de enfrentarse los ordenamientos de nuestros Estados, considerados democráticos y de derecho, en cuanto garantes de la libertad y la igualdad de sus ciudadanos, así como de la justicia de sus relaciones.

PaLABRAS CLAVE: Derechos humanos, Dignidad humana, Libertad religiosa, Ordenamientos democráticos, Poderes públicos.

ABSTRACT: The phenomenon of secularization in Western societies coincides with a growing public presence of intense religious phenomenon. The social dimension of the right of religious freedom in increasingly pluralistic societies is a true test of authenticity in contemporary democracies and their legal systems. The protection and promotion of religious pluralism by public authorities is one of the main challenges to the laws

${ }^{60}$ Sentencia del Tribunal Europeo de Derechos Humanos de 18 de febrero de 1999, Buscarini y otros contra San Marino. Doctrina reiterada en la Leyla Çahin contra Turquía, de 10 de noviembre de 2007. 
of our democratic states. States whose legal systems are presented as guarantors of freedom and equality of its citizens and the justice of their relations.

KEY WORDS: Human rights, Human dignity, Religious freedom, Democratic systems, Public powers.

Recibido: 21.05 .2012

Aceptado: 18.10 .2012 